HID 44 (2017)

\title{
LOS ÚLTIMOS GRADOS DE LA UNIVERSIDAD DE SOLSONA $(1701-1715)^{*}$
}

\author{
THE LAST DEGREES CONFERRED BY THE UNIVERSITY OF \\ SOLSONA (1701-1715)
}

\author{
Rafael Ramis Barceló \& Pedro Ramis Serra \\ Universitat de les Illes Balears - IEHM \\ r.ramis@uib.es
}

RESUMEN: En este artículo se estudian los últimos grados conferidos por la Universidad de Solsona (1701-1715). Con ello se pretende conocer mejor el perfil de los graduados por esta universidad irregular, que colacionó títulos de todas las Facultades a estudiantes catalanes y baleares, y que fue denunciada por la Universidad de Barcelona por práctica fraudulenta.

PALABRAS ClAVE: Solsona; grados; Universidad; siglo XVIII; estudiantes.

ABSTRACT: This article studies the last degrees conferred by the University of Solsona (1701-1715). Our aim is to draw a picture of the type of student who graduated from this unorthodox university which conferred degrees from all faculties on students from Catalonia and the Balearic Islands, and which was denounced by the University of Barcelona for fraudulent practice.

KEYWORDS: Solsona; degrees; university; $18^{\text {th }}$ century; students.

\section{INTRODUCCIÓN}

La Universidad de Solsona se creó supuestamente sobre la base de un Colegio que erigió la Orden de Predicadores en 1614, en la sede de un antiguo hospital, denominado d'en Llobera. La historia de la institución ha sido estudiada con cierto detalle a partir de los pocos materiales que quedaron después de la desaparición de buena parte del patrimonio archivístico eclesiástico y civil celsonense durante las diferentes guerras desde el siglo XVIII.

En realidad, la Universidad de Solsona era un modesto Colegio dominicano, que -con medios harto menguados-enseñaba exclusivamente Filosofía y Teología a sus religiosos y al clero secular de la diócesis. Con el apoyo tácito de las institu-

* Abreviaturas: ADS (Arxiu Diocesà de Solsona), AGOP (Archivum Generale Ordinis Praedicatorum), AHCB (Arxiu Històric de la Ciutat de Barcelona), AHCS (Arxiu Històric Comarcal del Solsonès), AHPA (Archivo Histórico de la Provincia de Aragón de la Orden de Predicadores). 
ciones eclesiásticas y civiles de Solsona, se arrogó los privilegios universitarios y empezó a graduar paulatinamente a dominicos y a seglares en todas las disciplinas. Pronto ese hecho fue conocido en las demás universidades del Principado, que comenzaron a preocuparse por la fuga de estudiantes hacia el Colegio de Solsona, del cual regresaban con una o varias borlas de bachiller o doctor en cualquier Facultad. La fama del colegio celsonense se extendió, pues sus grados eran muy asequibles, tanto en un sentido académico como económico.

La denominada Universidad de Solsona, que estuvo en funcionamiento -al parecer- desde 1620 hasta 1717, no sólo graduó de manera ilegítima, sino que lo hizo en todas las Facultades (Artes y Filosofía, Leyes, Cánones, Teología y Medicina), con lo que acudieron a dicha sede egresados de diferentes puntos del Principado de Cataluña y de las Islas Baleares.

En las páginas siguientes, tras un examen de las fuentes y de la bibliografía, se estudian los últimos grados colacionados por la Universidad, antes de que en 1717, por mandato de Felipe V, todas las Universidades catalanas fuesen transferidas a Cervera. Pretende ser una contribución a la historiografía de las Universidades y un análisis del final de una institución claramente fraudulenta a comienzos del siglo XVIII.

\section{FUENTES Y BIBLIOGRAFÍA}

La Universidad de Solsona ha sido una de las instituciones educativas más estudiadas de la Cataluña moderna, un hecho llamativo, dada la escasez de fuentes que han llegado hasta nuestros días. A la dispersión de éstas, sobre todo después de la transferencia de todas las Universidades catalanas a Cervera, debe sumarse la desamortización de los conventos y la destrucción de una parte importante del patrimonio archivístico durante la Guerra Civil española. De la Universidad de Solsona, así pues, han quedado muy pocos materiales de archivo, aunque no hay que descartar que algunos de ellos no hayan sido pasto del fuego o de la incuria y que, en algún momento, puedan ver parcialmente la luz.

En las búsquedas que hemos hecho en el Archivo Histórico de la Universidad de Barcelona hemos constatado algunas fuentes de las antiguas universidades municipales, aunque no hemos localizado manuscritos de las universidades conventuales que, en Cataluña, eran las de Solsona y Tortosa. Podría ser, aunque se trata de una circunstancia remota, que en fondos sin clasificar de los archivos de la Curia Romana de la Orden de Predicadores puedan aparecer más fuentes o que en una reordenación de los Archivos de Solsona salgan a la luz nuevos materiales. Tampoco el AHPA, sito actualmente en Valencia, aporta ningún tipo de documentación relevante para la historia de la Universidad.

Por el momento, disponemos de algunas fuentes notariales menores, todas ellas más o menos conocidas, aunque insuficientemente exploradas. Este estudio no se basa tanto en el protocolo del notario Pere Màrtir Coma, manuscrito del ADS con la rúbrica "Títulos e incorporaciones en la Universidad de 
Solsona", que contiene los primeros grados de los que se tiene noticia, sino en tres cuadernillos del mismo Archivo Diocesano sobre los grados en la última etapa de la Universidad, 1701-1715. Con ello se pretende atender algunos puntos que la historiografía anterior no pudo cubrir debidamente. Estos tres cuadernillos del ADS, de interés desigual para este estudio, son los que se describen a continuación.

El primero, con título borroso y subtítulo "Universitat literaria. Registre de graduats -1701 a 1714-" ${ }^{\prime 2}$ contiene los nombramientos de los Rectores. Tal documento sirve para completar la historia del convento y del colegio, trazada por Joan Serra Vilaró ${ }^{3}$, construida esencialmente sobre el manuscrito: "Llibre dels consells del Col·legi dels Sts. Arcangels Miquel i Gabriel den Llobera del Ordre de Predicadors de la ciutat de Solsona, comensant lo dia divuit de juliol del any 1640”, hallado de forma casual por el canónigo.

El segundo cuadernillo tiene la siguiente portada "+ Jesus Maria Joseph. Graduati in Sacra Theologia aliusque facultatibus in Universitate Collegii sanctorum Michaelis et Gabrielis den Llobera Ordinis Fratrum Praedicatorum civitatis Calsona a die vigessima prima mensis maii anni mellesimi septentigessimi primi de quibus constat per instrumentum apud Bernardum Coma auctoritatibus Apostolica et regia notarium publicum et dicta Universitatis secretarium recepta infra describantur ut in sequentibus foliis ${ }^{4 "}$. Es el protocolo notarial de los graduados durante los años 1701 a 1714, transcrito en el apéndice.

El tercer cuadernillo es un borrador del anterior, que contiene los datos "en sucio" de las diferentes colaciones de grado. Tiene el siguiente título: "Graduati in Sacra Theologia aliusque facultatibus in Universitate Collegii sanctorum Michaelis et Gabrielis den Llobera ordinis Fratrum Praedicatorum Civitatis Calsonae a die vigessima prima mensis Maii anni Millesimi Septingentissimi primus de quibus constat per instra apud Bernardum Coma nottarium et dicta Universitatis secretarium recepta, infra describuntur videlicet ${ }^{5}$. Este borrador resulta útil a la hora de corroborar algunos datos del otro cuadernillo y para poder añadir algunos pocos más al apéndice.

El AHCS conserva algunos documentos sueltos sobre la Universidad que, puestos en relación con otros materiales, iluminan algunos aspectos de la vida académica, como una copia notarial de 1648 de la bula pontificia y del documento de erección del Colegio ${ }^{6}$. De las fuentes inéditas del AHCS, algunas son externas a la propia Universidad de Solsona, aunque ayudan mucho a entenderla, especialmente en el tema de los privilegios y de los grados.

Con el acopio de estos materiales que no pudieron tener en cuenta los principales autores de la historiografía de la Universidad celsonense, se pueden modificar

1. ADS, Protocolos notariales, $n^{\circ} 167$, ff. $27 \mathrm{r}-29 \mathrm{v}$.

2. $\mathrm{ADS}, \mathrm{n}^{\circ} 319,9 \mathrm{ff}$.

3. Serra Vilaró 1953.

4. ADS, $n^{\circ} 319$, s.n.

5. ADS, $n^{\circ} 319$, s.n. De otra mano se lee, al final, "Universitat Literaria".

6. AHCS, Leg. 87, núm. 73. 
algunas de las tesis básicas sostenidas hasta ahora. Pocas son las referencias a la Universidad de Solsona en las obras históricas del siglo XVIII. Hay una breve alusión en el Viage de España de Antonio Ponz ${ }^{7}$, en la que se indica que el convento de los dominicos fue Universidad hasta la erección de la sede de Cervera.

En el siglo XIX hubo algunas referencias a la Universidad de Solsona, aunque todas ellas repetían casi siempre los mismos contenidos, a saber: se trataba de un Colegio fundado por los dominicos sobre un antiguo hospital, que recibió privilegio papal que lo transformaba en Universidad y le permitía conferir grados. Es la idea que, por ejemplo, transmitió Jaime Villanueva en su Viage literario a las iglesias de España ${ }^{8}$. Por su parte, Torres Amat, refiriéndose a la Universidad de Solsona, indicó lo siguiente: "que los PP. dominicos de esta ciudad conferian grados literarios, consta por una declaracion y representacion contra ellos, que existe en la biblioteca episcopal de Vich, var. 1.1. fol. 197"9.

Más allá de noticias aisladas que dieron $\mathrm{Madoz}^{10}$ y Fernández de las Cuevas ${ }^{11}$, la Universidad de Solsona tuvo un tratamiento escasísimo en la obra de Vicente de la Fuente, en la que se trazaba una visión de conjunto de las Universidades hispanas, en las que el Principado de Cataluña fue estudiado con muy poco detalle, especialmente en comparación con Castilla. De Solsona indicó que "ni aun habría apenas noticia de tal Universidad, sino hubiese dejado algunas, aunque casi insignificantes, el P. Villanueva en su Viaje literario ${ }^{12}$ ". Poco más sabía este autor, que volvió a mencionar muy de pasada la Universidad de Solsona, al explicar la transferencia de todas las sedes a Cervera en $1717^{13}$.

Puede decirse, por lo tanto, que durante el siglo XIX, el desconocimiento sobre la Universidad de Solsona fue casi absoluto. Y pocos cambios se dieron durante la primera mitad del siglo XX. En un tratado anónimo sobre la diócesis de Solsona, publicado en 1904, se dieron algunas noticias aisladas sobre la Universidad ${ }^{14}$. Por su parte, Pedro Sanahuja, buen historiador de la Universidad ilerdense medieval, repitió las mismas ideas que ya se encontraban en Villanueva ${ }^{15}$ y en la Enciclopedia Espasa ${ }^{16}$.

La gran obra sobre la Universidad celsonense la publicó el canónigo Joan Serra Vilaró en 1953, que tuvo la habilidad y la fortuna de hallar durante su etapa como Director del Museo Diocesano de Solsona algunos materiales imprescindibles so-

7. Ponz 1788 , p. 145.

8. Villanueva 1821, p. 73. “...erigio en colegio de padres dominicos la casa hospital llamada comunmente den Llobera, fundada en 1411 por Francisca, muger de Bernardo Guillem de Peramola. Verificose la nueva fundación en 1617, y tres años después fue erigida en universidad, con facultad de conferir grados, que disfrutó casi un siglo, hasta la reunión de todas las de esta provincia con la de Cervera".

9. Torres Amat 1836, pp. 717-718.

10. Madoz 1847, pp. 346-347.

11. Fernández de las Cuevas 1852, p. 522.

12. De la Fuente 1970, p. 409.

13. Ibid., III, pp. 223-224.

14. Anónimo 1904.

15. Sanahuja 1944, p. 33

16. AAVV 1927, p. 209. 
bre la historia de la Universidad, si bien muchos de ellos fueron quemados o se perdieron durante la Guerra Civil y no los pudo tener en cuenta para la elaboración definitiva de su obra.

Aunque Serra Vilaró pudo conocer los libros de grados y otros manuscritos, desafortunadamente no tomó nota de su contenido antes de la contienda bélica. Pese a la destrucción de este patrimonio, la fortuna hizo que en su momento el P. Vicente Beltrán de Heredia, que estaba llevando a cabo la historia de las instituciones educativas hispánicas durante las primeras décadas del siglo XX, pudiese consultar un importante volumen manuscrito sobre la historia de la institución celsonense. Al poco tiempo de aparecer la obra de Serra Vilaró, Beltrán de Heredia publicó primero una recensión ${ }^{17}$ en la que daba cuenta de algunas lagunas e imprecisiones en la obra de Serra a la vista de los contenidos que él había tomado del manuscrito hoy perdido. Al cabo de unos años publicó un artículo $^{18}$ en el que daba la nómina de los colegiales, lectores de artes, maestros de estudiantes, lectores de teología y rectores del Colegio, copiada fielmente del manuscrito indicado.

Con ello se completaba mucho la labor de Serra Vilaró, quien se guió por algunos documentos inéditos que halló sobre la Universidad y, muy especialmente, como hemos indicado antes, por el manuscrito "Llibre dels consells del Col·legi dels Sts. Arcangels Miquel i Gabriel den Llobera..." sobre el Colegio, en el que se detallaba la vida de muchos de los frailes que lo moraron. El libro de Serra Vilaró se ocupaba más del Colegio y de los dominicos que de la propia vida universitaria, sobre la que recogió los escasos materiales que encontró.

Tanto Serra Vilaró como el propio P. Beltrán de Heredia hicieron gala de una visión objetiva y positivista, siempre rigurosamente apoyada en las fuentes. De ahí que pueda decirse que las líneas maestras de historia de la institución han salido de sus plumas. Ambos aportaron datos sobre toda la información que hallaron y evitaron los juicios críticos sobre el Colegio. Sus trabajos tenían un carácter eminentemente descriptivo, continuado después por el resto de la historiografía, que asumió sus datos y los ha ido repitiendo.

Una visión bastante más crítica sobre el surgimiento de la Universidad de Solsona la dio Cándido M. Ajo en su monumental historia de las Universidades hispánicas ${ }^{19}$. Ajo puso en tela de juicio el ortorgamiento de los privilegios pontificios para colacionar grados. Pese a ello, el libro de Serra Vilaró y el artículo de Beltrán de Heredia fueron la base de la historiografía posterior, que apenas mostró modificaciones. Desde Vicens Vives ${ }^{20}$ a García Cárcel ${ }^{21}$, los estudiosos continuaron con las mismas referencias ${ }^{22}$. Incluso en una obra dedicada a la historia de las Universidades catalanas del siglo XVII como fue la de Eufemià Fort i Cogul, que

17. Beltrán de Heredia 1955, p. 499.

18. Beltrán de Heredia 1958, pp. 125-137.

19. Ajo, 1959, pp. 67-70.

20. Vicens Vives 1961, p. 586.

21. García Cárcel 1985, p. 438.

22. Parramon Doll 1975, pp. 201-212. 
firmaba bajo el pseudónimo de A. Folch ${ }^{23}$, que tenía un carácter eminentemente descriptivo, no había ninguna novedad en la explicación del caso celsonense.

Sin embargo, hubo algunos opúsculos de interés (que han pasado prácticamente inadvertidos) como el de Antonio Llorens Solée ${ }^{24}$, canónigo archivero de la Catedral de Solsona. En este breve trabajo, el autor notó algunas de las carencias en la obra de Serra Vilaró y dio a conocer tres fuentes inexploradas: el testamento de Francisca de Llobera, la creación de la Cofradía de San Nicolás y algunos datos sobre los cuadernillos sobre grados descritos en el apartado anterior. Por desgracia, el trabajo de Llorens no reproducía los grados, sino que daba unas cuantas noticias generales. Por ello, en el apéndice hay una transcripción integral de estos graduados.

Sobre éstos llevó a cabo una pequeña incursión Daniel Montañà Buchaca ${ }^{25}$, quien elaboró un breve estudio sobre las vicisitudes de los graduados en Medicina en esa Universidad que colacionaba grados sin tener Facultad de esa especialidad. Por su parte, Ramon Planas i Albets publicó una síntesis con una aproximación a los estatutos de la institución ${ }^{26}$.

En un libro colectivo sobre las Universidades catalanas coordinado por Busqueta y Pemán no se estudió específicamente la Universidad de Solsona, aunque Lahoz y Gort ${ }^{27}$ publicaron una bibliografía general sobre las Universidades catalanas, que recogía acertadamente los títulos de las publicaciones sobre la sede celsonense.

En la primera década del siglo XXI, Eduardo Escartín publicó dos artículos en los que estudiaba indirectamente algunos aspectos de la Universidad de Solsona, a través de una polémica universitaria ${ }^{28}$ sobre las graduaciones. Publicamos hace muy poco un trabajo sobre los privilegios y los grados universitarios de la Universidad de Solsona ${ }^{29}$, atendiendo a la controvertida cuestión de los privilegios con los que graduaba (con una discusión sobre su validez jurídica). Con ello queríamos sostener la tesis que, en realidad, la Universidad jamás tuvo privilegios pontificios para graduar y que todos los grados que este centro confirió fueron sin legitimidad jurídica, pues no había ningún título legal que los amparase.

Finalmente, en 2016 Ramon Planas Albets ${ }^{30}$ ha publicado una voluminosa y pormenorizada historia del Hospital d'en Llobera, con un nutrido apéndice documental, que arroja mucha luz sobre algunos aspectos universitarios y pasa a ser la obra de referencia sobre la institución.

23. Folch 1972, pp. 54-61.

24. Llorens i Solé 1978, pp. 95-101.

25. Montañà i Buchaca 1988, pp. 247-56.

26. Planes i Albets 1984, pp. 369-374.

27. Lahoz Finestres y Gort Riera, pp. 603-665, especialmente p. 651.

28. Escartín Sánchez 2003, pp. 187-202.

29. Ramis Barceló 2015, pp. 661-678.

30. Planes Albets, 2016. 


\section{LOS GRADUADOS 1701-1715}

El caudal más rico de datos sobre los grados universitarios se encuentra en estos cuadernillos ya indicados, pues cubren los graduados de la última etapa de la institución, durante los rectorados de Tomàs Bransi, Pere Màrtir Samasada y Gabriel Dalmau ${ }^{31}$. Los maestros más relevantes en este período fueron los siguientes, a saber:

- Fr. Pere M. Samasada, hijo del convento de Girona y procedente de $\mathrm{Vic}^{32}$, maestro de artes en Solsona en $1691^{33}$, maestro de estudiantes en 1695 , lector de teología en 1698, y rector entre los años 1705-1709 y 1712-1715.

- Fr. Tomàs Bransi, lector de teología e hijo del convento de Barcelona fue el rector del Colegio en 1701 y fue nombrado de nuevo en 1704³. Ejerció hasta 1705 .

- Fr. Diego March, hijo del convento de Barcelona, fue maestro de artes en $1693^{35}$, y lector de teología en 1701.

- Fr. Ramon Bages, hijo del convento de Santa Catalina, donde fue colegial del colegio de San Vicente y San Raimundo de Barcelona ${ }^{36}$, maestro de artes desde $1698^{37}$, maestro de estudiantes en 1705 , lector de teología en 1707 y rector en 1715 .

- Fr. Pere M. Monjo, hijo del convento de Barcelona, donde fue colegial del colegio de San Vicente y San Raimundo de Barcelona ${ }^{38}$ en 1702 y luego pasó a ser maestro de artes en Solsona en $1704^{39}$, maestro de estudiantes en 1707 y lector de teología en 1710.

- Fr. Esteve Silvestre, que fue lector de artes en $1710^{40}$, maestro de estudiantes en 1714 y lector de teología en 1716.

- Fr. Gabriel Dalmau, hijo del convento de Barcelona, fue nombrado rector en $1709^{41}$.

La Universidad no tuvo Rector, salvo en momentos esporádicos ${ }^{42}$. El Rector del Colegio aparecía en ocasiones como Rector y Canciller de la Universidad. Al ser una universidad irregular, el Rector y el vicerrector del Colegio eran indistintamente los cancilleres de la Universidad y ellos conferían los grados. En el anexo puede verse que los grados los conferían el Rector o el Vicerrector, que en algunos

31. Beltrán de Heredia 1958, p. 135.

32. Collell 1960, pp. 309-331, concretamente, p. 319.

33. Beltrán de Heredia 1958, p. 131.

34. Ibid., p. 135.

35. Id., p. 131.

36. Collell 1960, p. 319

37. Beltrán de Heredia 1958, p. 131.

38. Collell 1960, p. 320.

39. Beltrán de Heredia 1958, p. 131 y ss.

40. Ibid., p. 131.

41. Id., p. 135.

42. Planes Albets, 2016, pp. 180-183. 
casos fungían también como padrinos del graduado, tal y como puede verse con Fr. Tomàs Bransi y los primeros graduados que se estudian.

Los grados resultaban sumamente baratos. Según la alegación del Dr. Lluís de Valencià, catedrático de la Universidad de Barcelona:

"Algunos de los que van à Graduarse a Solsona, preguntados, como assi Despre-
cian las Vniversidades en que an Cursado? Responden (omitiendo la Principal
Respuesta del facil Despacho) que no ${ }^{43}$ pagan sino 28 Reales de à Ocho por todas
las Propinas. I si se les Replica de que les à de Aprovechar el Grado?, dizen, que
para traer Muceta Morada en las Iglesias, i los que van fuera Reino, porque el
Privilegio, que dan los Padres Dominicos dize en la Narrativa, que aquello es Vni-
versidad, i los Privilegio de Barcelona, solo se Condecoran con Titulo de Estudios
Generales. Respuestas son verdaderamente dignas de Grado Diminuto..."

El resto de universidades catalanas se oponían a la Universidad de Solsona. Había a la sazón cuatro universidades municipales (Lérida, Barcelona, Vic y Gerona), dos conventuales (Tortosa y Solsona) y un Seminario-Universidad (Tarragona). Las más reputadas eran las de Barcelona ${ }^{45}$ y Lérida $^{46}$, que continuamente se quejaban de los abusos de Solsona. La Universidad de Vic tenía un carácter más bien local y la de Gerona había empezado a funcionar definitivamente pocos años antes de la Guerra de Sucesión. La Universidad de Tortosa ${ }^{47}$ era un colegio de dominicos, con privilegios reales y pontificios, que sólo enseñaba y graduaba en Artes y en Filosofía. Los universitarios catalanes solían graduarse también en la Universidad de Huesca ${ }^{48}$ o en la de Roma ${ }^{49}$, donde aparecen muchos doctores en ambos derechos pertenecientes al estamento eclesiástico.

Sentado lo anterior, vamos a exponer los grados de Solsona de acuerdo con las especialidades (que no según las Facultades, pues formalmente no existían), conforme a la transcripción que hizo Bernat Coma, notario público, quien -según se indica en la documentación- falleció entre las dos y las tres de la madrugada del 10 de agosto de $1714^{50}$.

\section{a. Filosofía}

Los graduados en Filosofía apenas llegaban a la docena, lo cual indica que se trataba de una sede a la que los interesados acudían en busca de los grados de las Facultades mayores. Entre los rasgos más sobresalientes como colectivo destaca su pertenencia exclusiva al clero y su procedencia catalana. No hubo, durante este

43. Sic, en el ejemplar de la alegación consultada.

44. AHCB, Estudi General, leg. AJ-V-10, f. 41.

45. Ramis Barceló 2016, pp. 385-408.

46. Véase Esteve Perendreu 2007.

47. Querol Coll 2013.

48. Lahoz Finestres 1997, pp. 167-220.

49. Ramis Barceló 2017.

50. ADS, n ${ }^{\circ} 319$, cuaderno, s.f. 
período, graduados en Filosofía de Baleares. La mayoría de ellos necesitaban el bachillerato y la licenciatura en Artes para poder acceder a estudios superiores o bien para su propia promoción eclesial. Sólo la mitad de ellos alcanzó el rango de doctor, hecho que les facultaba para la docencia de las Artes y de la Filosofía.

Al analizar las procedencias nos percatamos de que muchos de ellos, tal y como sucedía en muchas Universidades, acudían en grupo a graduarse, sufragando los gastos conjuntamente y protegiéndose de peligros. Es el caso de Bernat Coma, Josep Enrich, Miquel Sastre y Francesc Vinyals, todos ellos clérigos de Manresa. Los tres primeros se graduaron el mismo día, mientras que el último lo hizo dos días después.

Se graduaron también Jacint Cristòfol ${ }^{51}$, procedente de Granollers, Tomàs Villaró y Ramón Nadal, profesor de Filosofía en Guissona. El mismo día se graduaron de licenciado y doctor Juan Vendament, presbítero de Barcelona y Francisco de Llisachs, presbítero de Santpedor. Finalmente, recibieron también los mismos grados, Antonio Vila, clérigo de Solsona y Josep Abadal, presbítero de Calaf.

Cabe subrayar que en las colaciones a veces el Rector era el Canciller y el padrino. Había siempre los pocos profesores dominicos y algún clérigo local. Hay que destacar, tanto en los grados de filosofía como en los que vienen a continuación, la presencia ubicua de Antoni Pallarés, doctor en ambos derechos y asesor de la Ciudad ${ }^{52}$. En algunos casos asistían como testigos algunos menestrales (zapateros, cereros, manufactureros de velos...).

\section{b. Teología}

La nómina más amplia de graduados fue la de teología, repartidos entre miembros del clero secular y regular. Entre los clérigos seculares había presbíteros o aspirantes al sacerdocio de Solsona y de ciudades o localidades del Principado. Algunos de ellos ocupaban un curato, beneficio o canonjía, mientras que del resto sólo conocemos su condición eclesiástica. Los aspirantes al grado procedentes del clero regular se repartían entre dos órdenes afectas a la filosofía de Santo Tomás: los propios dominicos, titulares del Colegio, y los carmelitas.

Cabe notar la presencia de varios candidatos baleares, tanto carmelitas como del clero secular. En la Universidad Luliana y Literaria de Mallorca desde 1692 se enseñaba teología por cuatro vías: lulista ${ }^{53}$, escotista ${ }^{54}$, suarista $^{55}$ y tomista $^{56}$. Resulta claro que los graduados baleares que aquí aparecen profesaban la vía tomista.

Intentemos seguir un orden cronológico para conocer mejor a los graduados. Los dos primeros de los que tenemos noticia son sendos dominicos, que recibieron

51. El manuscrito, en vez de indicar que se trataba de un grado en Filosofía, como en los demás, señala que fue en Artes.

52. AHCS, leg. 90, núm. 82, s. f.

53. Ramis Barceló 2014a, pp. 185-205.

54. Ramis Barceló 2015b, pp. 301-317.

55. Ramis Barceló 2014b, pp. 399-426.

56. Ramis Barceló 2013, pp. 345-368. 
el bachillerato y la licenciatura el mismo día. Fr. Pere Escorcell era colegial del Colegio de San Vicente y San Raimundo de Barcelona ${ }^{57}$ y se graduó junto a Fr. Domènec Daniel. En esa fecha recibió también los grados el carmelita Fr. Albert Torres, mientras que Fr. Àngel Fabregues y Fr. Josep Roca, también carmelitas, se graduaron al cabo de una semana.

Seguidamente recibieron los grados Pere-Joan Cardona ${ }^{58}$, clérigo de Solsona, Joaquim Llanes, canónigo de Manresa, Urbicio Closa, Rector de Salelles y Joan Carreres, clérigo de Manresa. Se graduó también Pere M. Andreu i de Miquel ${ }^{59}$, canónigo de la Catedral de Solsona. El 13 de julio de 1701 se graduaron dos carmelitas: Fr. Albert Peres y Fr. Francesc Font.

Se graduaron también varios baleares: el mismo día, Francisco Tallades, diácono de Campos (Mallorca), y Antonio Ribot, diácono mallorquín ${ }^{60}$. Asimismo recibieron el bachillerato, la licenciatura y el doctorado, nemine discrepante, Miguel Carbonell y Joan Oliver de Ciutadella.

Antoni Coma, presbítero de Solsona, Miquel Ribot, Beneficiado de Girona y Gabriel Mir, subdiácono de Menorca recabaron los mismos grados. Cabe notar que a estos estudiantes menorquines no los hemos podido documentar en los libros de grados de la Universidad Luliana, lo cual hace pensar que obtuvieron el bachillerato en artes en otra sede. Tampoco hemos documentado entre los graduados en la Universidad mallorquina a Llorenç Salvà, reverendo de la Ciudad de Mallorca, Jaime Peregrí, carmelita del convento de Palma ${ }^{61}$ y Josep Llabrés, que había recibido el subdiaconato en Palma. Los tres recibieron el bachillerato, la licenciatura y el doctorado nemine discrepante.

Francisco Nuix, presbítero de Cervera, perteneciente a una de las más importantes familias de la ciudad, se graduó de bachiller, licenciado y doctor, el mismo día que Jerónimo Riber, presbítero y beneficiado de Solsona. Josep Ribes, presbítero de Manresa y Josep Vallonga ${ }^{62}$, clérigo de Solsona recibieron los mismos grados, al igual que Pedro Coranti, clérigo de Maó, y Fr. Pere Tomàs Catany, carmelita. Asimismo se graduaron Josep Cerch (o Sech), Rector de Ozea o de Ossea, en la diócesis de Solsona; Francisco Carulla, Vicario perpetuo de Sant Miquel de Castellvell; el carmelita Fr. Juan Antonio Barceló, procedente del convento de Palma, y Juan Lluch i Azamor, presbítero de Solsona.

En 1705 se graduaron Fr. Alberto Serralta, carmelita del convento de Palma; y Lluís Pallarés, clérigo de Solsona y Juan Molinou, de quien no tenemos información. Al año siguiente recibieron los grados de licenciado y doctor Pere Tur, presbítero de la villa de Ibiza; Ramon Huguet, presbítero de Cervera; y Marco Antonio

57. Collell 1960, p. 320.

58. Planes Albets, 2016, pp. 313-314.

59. Dietari de la Generalitat de Catalunya, 1994, p. 734.

60. Hay un autor homónimo graduado como Bachiller en Artes en la Universidad Luliana el 3 de junio de 1698. Véase Cassanyes Roig y Ramis Barceló, 2014, p. 20.

61. Bover 1868, p. 86. Fue lector de Teología, examinador sinodal del obispado de Mallorca y calificador del Santo Oficio. Murió el 8 de agosto de 1730.

62. Hay un autor homónimo entre los exiliados durante la Guerra de Sucesión. Véase Albareda Salvadó 2005, pp. 51-64, especialmente p. 58. 
Capdevila, presbítero de Talarn. En 1707 se doctoraron Onofre Planes, presbítero de Vallfogona; Josep Taltavull, diácono de Ciutadella; Josep Prats i Ponsich, clérigo de Barcelona; y Josep Botines, clérigo de Solsona.

Al año siguiente, 1708, se graduaron de licenciado y doctor Marco Olives, diácono de Ciutadella; Francisco Aymerich, presbítero de Ribes de Freser; Isidro Font, clérigo de Solsona, Miquel Dameto, reverendo de Palma y Fr. Tomás Llanés, dominico, que desde ese año fue maestro de Artes en el Colegio ${ }^{63}$. En 1709 se licenciaron y se doctoraron, nemine discrepante, Fr. Francisco Melià, carmelita; Francisco Danús, clérigo de Llucmajor, en Mallorca; Francesc Llaneres, clérigo de Solsona; Josep Pujol, presbítero de la misma ciudad; Fr. Gabriel Dalmau, dominico hijo del convento de Barcelona, que fue el Rector a partir de ese año, como hemos indicado antes; Francisco Andreu y de Miguel, clérigo celsonense y profesor de Teología, y Magí Solans, prebítero y Rector de Oliana, en la diócesis de Urgell.

En 1710 se licenciaron y doctoraron, todos ellos con la máxima calificación, nemine discrepante: Bernat Coma, clérigo de Manresa; Jaume Argullol, presbítero y beneficiado de Calaf; Juan Bautista Suau, clérigo de la Ciudad de Mallorca; Josep Vilanova, acólito de Banat; Fr. Esteve Silvestre, dominico, que procedía de Girona y que en 1703 había sido colegial en el Colegio de San Vicente y San Raimundo ${ }^{64}$; Magí Bagués, presbítero de Pons y Rector de la Iglesia de la Torra; y finalmente Josep Grau, presbítero celsonense.

En los últimos años, por mor de la Guerra de Sucesión, las colaciones se espaciaron mucho. Recibieron los grados de licenciado y de doctor, siempre nemine discrepante, Josep Ruet y Miguel Barceló, presbítero beneficiado de Ciutadella ${ }^{65}$; Salvador Francisco Serra, diácono de Sa Pobla (Mallorca); Jerónimo Ardén, clérigo de Solsona que había actuado como testigo en muchos exámenes; Juan Bautista Forner, presbítero beneficiado de la Catedral de Ibiza, que había ejercido como profesor de Gramática en la isla ${ }^{66}$; Ramon Castelló, presbítero de Cervera, Francisco Font, diácono de Solsona y Josep Janer, presbítero de Cervera.

Los dos últimos casos son excepcionales: la licenciatura y el doctorado de Domingo de Ausmendi, de la destacada familia de los Ausmendi o Auzmendi ${ }^{67}$, procedente de Villarreal (de Urrechua) y Fr. Antonino Genée, dominico de la Provincia de la Germania inferior, graduado el último día de 1715.

\section{c. Leyes y Cánones}

Fueron escasos los títulos en leyes y cánones durante el período del que tenemos datos manuscritos. Fueron, sin duda, muchos más en años anteriores, especialmente antes de la fundación de la Universidad Luliana y Literaria de Mallorca.

\footnotetext{
63. Beltrán de Heredia 1958, p. 131.

64. Collell 1960, p. 320.

65. Con el tiempo llegaría a ser Vicario General de la Isla. Cf. Ramis y Ramis 1817, p. 28.

66. Planells i Ripoll, 1995, pp. 59-63, especialmente p. 61.

67. Guerra 1928, pp. 99-100.
} 
De hecho, no hubo ningún jurista ni canonista mallorquín, lo cual indica que preferían graduarse en la recién inaugurada universidad insular.

Los seis grados se reparten de manera muy equilibrada entre menorquines y catalanes, y entre legistas y canonistas, pues corresponden a tres en cada grupo. De hecho, todos los legistas eran menorquines, y podían ejercer el derecho en su tierra de origen sin nungún tipo de objeción legal. Los tres fueron Pere Antoni Carrió y Rafael Albertí, de Ciutadella, y Cosme Albertí, de Alaior. Sabemos que algunos de ellos llegaron a ejercer. Hay varios personajes homónimos llamados Pere Antoni Carrió: uno fue pavorde interino ${ }^{68} \mathrm{y}$ otro es identificado como escribano, notario y secretario de la curia eclesiástica de Menorca.

Joan Ramis destacó asismismo, de los otros dos graduados menorquines, lo siguiente: "En 1706 encuentro al Muy Reverendo Dr. Cosme Alberti Presbitero, y comisario del Santo Oficio en Ciudadela y finalmente al Magnifico Dr. Rafael Alberti y Garibaldo con el empleo de Abogado Fiscal Real, y Patrimonial desde 1712 á $1722^{69}$ ".

Los tres canonistas eran catalanes. El primero de ellos, Jacinto Caballol, era un reverendo de Oliana, localidad donde a instancias de su padre se establecieron las Escuelas Pías. Caballol fue procurador de los bienes de un exiliado austracista ${ }^{70}$. Otro fue Josep Indilla, presbítero de Cervera y miembro de una estirpe que años después tendría mucho peso en la Universidad borbónica de la Ciudad.

Posiblemente, de todos los graduados en esta época el más importante fuese Francesc de Josa i Agulló, quien se doctoró en cánones en la sede celsonense, tras haber cursado estudios en otras sedes. Hijo de Guillem Ramon de Josa i de Peguera, señor de Altés y de Pinós, nuestro personaje nació en Barcelona hacia 1671. Sucedió a su tío paterno Luis en los cargos de arcediano de Santa María del Mar, canónigo de la Catedral de Barcelona y Vicario general de esta diócesis. Fue miembro de la Acadèmia dels Desconfiats, fundada en 1700 en Barcelona por catorce eruditos, cuya principal misión era la promoción del estudio de la historia, la lengua y la poesía catalanas. En 1713 acompañó al obispo de Barcelona, Benet de Sala i Caramany, a recibir el capelo cardenalicio de manos del Papa. Fue acusado de haber tenido simpatías austracistas ${ }^{71}$ y Felipe V le mandó regresar a Barcelona de inmediato. Se negó a obedecer y fue nombrado comisario general de la Cruzada en Sicilia, con un sueldo de diez mil florines ${ }^{72}$. Murió en la Ciudad Eterna en $1721^{73}$.

Los examinadores para la obtención de los grados fueron algunos juristas, canonistas o teólogos de la Ciudad, tales como José Planes, Canónigo de Tortosa; Josep Llobet, doctor en teología, Josep Folch y Tomás Villaro, Doctores, y espe-

68. Ramis y Ramis 1817, p. 54.

69. Ibid., p. 12.

70. Florensa i Parés 2010, p. 46.

71. Su hermano mayor, Joan, fue un fiel filipista. Véase la disensión entre hermanos en Molas Ribalta, 2008, pp. 263-280, especialmente p. 267.

72. Alcoberro 2002, p. 84.

73. Ochoa Brun 2002, p. 78. 
cialmente el ya citado Antoni Pallarés, que en algunos casos fungió como padrino. Asimismo, Gabriel Dalmau, fue doctor en cánones, tal y como se indica varias veces en la documentación.

\section{d. Medicina}

En la Pragmática de 4 de noviembre de 1617 se fijaron las normas para la formación de los médicos y el ejercicio de la medicina y la cirugía. Por esta cédula quedó instituido que sólo en aquellas universidades que se leyeran cátedras de Prima, Vísperas, Cirugía y Anatomía se podía otorgar el grado de bachiller en Medicina. Además, se estableció que ese grado sólo se daría si se hallaban presentes siete médicos doctores e incorporados en esa universidad y "si no se completare el número, en dos o tres, podrían asistir licenciados también graduados con la presencia del catedrático de Filosofía Natural ${ }^{74}$ ". El incumplimiento de esa norma fue sistemático en los conventos-universidad y, con mayor motivo, en Solsona.

En esta época sólo hemos encontrado tres candidatos que se licenciaron y se doctoraron, nemine discrepante, en Solsona. Es curioso que ninguno de ellos obtuvo el bachillerato en Solsona, sino la licenciatura y el doctorado, que, en general, no eran los títulos habilitantes para el desempeño práctico, sino los de carácter más bien honorífico.

En estos casos, los examinadores fueron doctores de medicina: Bernardino Parent, Carlos Reygada, Francisco Crech y Pedro Pujol. Los tres casos se dieron en los años 1709-1711, en el marco de la Guerra de Sucesión. Fueron Miquel Mulet ${ }^{75}$, de la villa de Algaida, Juan Pons ${ }^{76}$, de Binissalem, ambas en Mallorca y Josep Joan Riquer, de Ibiza. No tenemos datos de la actividad práctica de Mulet y de Pons (de éste último consta en la documentación que era bachiller en Medicina, sin especificar en qué universidad había obtenido el título), aunque sí de Riquer, apodado "Torrent", hijo de un cerrajero, natural de Ibiza ${ }^{77}$, donde fue durante treinta y dos años el médico municipal, sin recibir paga alguna. Se intentó compensar su dedicación nombrándolo médico del morbo. En su condición de doctor en medicina, según Planells, desempeñó varios cargos representativos del brazo mayor: jurado segundo entre 1716 y 1723 y regidor segundo entre los años 1734-1735.

Existieron, pues, los grados de medicina en Solsona prácticamente hasta su clausura; en la época final no se prodigaron tanto como en otras, aunque dejaron su huella en la universidad celsonense. Sin duda, la Universidad de Solsona hizo caso omiso a las peticiones elevadas al virrey por la Universidad de Barcelona y siguió graduando hasta el final de la Guerra de Sucesión.

74. Hernández Morejón 1842, p. 148

75. Planes Albets 2016, pp. 325-326.

76. Hay un personaje homónimo graduado de bachiller en Artes en la Universidad Luliana el 11 de Febrero de 1708. Véase Cassanyes Roig y Ramis Barceló, 2014, p. 24.

77. Planells Ripoll 1996, pp. 160-165. 


\section{EPÍLOGO Y CONCLUSIONES}

Tras el Decreto dado en El Pardo el 17 de agosto de $1717^{78}$, todas las Universidades catalanas quedaban transferidas a Cervera, sede a la que tenían que incorporar asimismo sus rentas. El 12 de noviembre, Felipe V prohibió todos los grados y estudios superiores en las Universidades transferidas ${ }^{79}$. De esta forma, el mapa universitario catalán quedaba recompuesto en una sola sede y se dejaron de colacionar grados en el Principado.

En la sede celsonense hubo pocos cambios, puesto que los bienes de la Orden fueron exceptuados de su transferencia y persistió el Convento de Sant Miquel en su función colegial. Dicho de otro modo, en 1717, tras la Guerra y después de sufrir destrozos, perdió la facultad de graduar, aunque no dejó de ser un Colegio ni de tener sus rentas. Por lo tanto, volvió a ser lo que era en 1614: un pequeño Colegio de la orden, con pocos maestros, donde se formaban algunos dominicos y miembros del clero local.

Resulta curioso que, a lo largo del siglo XVIII, el Colegio de Solsona gozase de un trato mucho más privilegiado que el de otras sedes universitarias, especialmente tras la adhesión de los dominicos a la causa del archiduque Carlos. Parece ser que Solsona, por su cercanía con Cervera, mantuvo algunos privilegios en el ámbito de la incorporación de los cursos para los grados, de manera que el Colegio siguió realizando -mejor o peor- su labor y tuvo su reconocimiento en la Universidad cervariense.

Subrayó Cándido $\mathrm{Ajo}^{80}$ que los grados del Colegio de Solsona fueron válidos jurídicamente desde el 28 de agosto de 1733, cuando el papa Clemente XII, concedió a todos los gimnasios o casas de estudio de la Orden la posibilidad de conferir grados, incluso de doctor a sus propios religiosos y a los demás que cursasen debidamente las materias y fuesen examinados ${ }^{81}$. Según este autor, tales privilegios sirvieron para graduar a algunos dominicos, carmelitas o seglares ${ }^{82}$, aunque no tenemos ninguna constancia de ello y los datos sobre los que se apoya para tal afirmación no han podido ser contrastados.

A nuestro entender, a partir de 1717 Solsona dejó de graduar y de considerarse Universidad. Subsistieron ciertamente los cursos de Artes y de Teología, según había indicado ya Beltrán de Heredia, y continuó la vida colegial y conventual, como han mostrado Serra Vilaró y Planes Albets.

Hay que concluir que la Universidad de Solsona graduó de forma irregular y que su radio de atracción fue el Principado de Cataluña y Baleares. En esta época final graduó esencialmente a clérigos y debe observarse que sólo graduó en Medicina y en Leyes a los estudiantes baleares. ¿Por qué se aceptaban los títulos celsonenses en las islas? Básicamente porque en ellas, dados los peligros del mar

\footnotetext{
78. Transcrito en Ajo 1963, pp. 197-198.

79. Ibid., pp. 199-200.

80. Ajo 1966, p. 484.

81. Ajo 1963, pp. 265-268

82. Ajo 1966, p. 485.
} 
y la dificultad en las comunicaciones, muy pocos sabían lo que sucedía realmente en Solsona.

Resulta llamativo que los mallorquines, teniendo universidad desde 1692, continuasen acudiendo a Solsona. Podría pensarse que, puestos a buscar un título fácil y barato y en la tesitura de salir de sus respectivas islas, a menorquines e ibicencos les salía más a cuenta desplazarse hasta Solsona. Sin embargo, el caso mallorquín muestra cuán fáciles y apetecibles eran los grados celsonenses, para que tanto clérigos como laicos sorteasen los peligros del mar y de la tierra para llegar al Colegio de Sant Miquel en búsqueda de los títulos.

Entre los graduados catalanes hay que destacar, por último, que la mayoría fueron hijos del obispado de Solsona o de diócesis vecinas. En su mayoría no fueron personajes muy destacados. Hubo alguna excepción notable, como Francesc de Josa i Agulló, Arcediano de Santa María del Mar.

En fin, la aventura universitaria que hacia 1620 emprendieron los dominicos en Solsona, por su cuenta y riesgo, y con la tácita aprobación de la Ciudad y del Obispo, duró casi cien años. Si no se hubiesen perdido los libros de grados, tendríamos completa noticia de los centenares de egresados por esa dudosa sede que, no por su práctica corrupta, sino por castigo de Felipe V, dejó de llenar en 1717 tanto Cataluña como Baleares de titulados a veintiocho reales.

\section{APÉNDICE DOCUMENTAL ${ }^{83}$}

Grados conferidos entre 1700 y 1715

ADS, no 319, cuaderno.

Jesus Maria Joseph

Graduati in Sacra Theologia aliusque facultatibus in Universitate Collegii sanctorum Michaelis et Gabrielis den Llobera Ordinis Fratrum Praedicatorum civitatis Calsona a die vigessima prima mensis maii anni millesimi septentigessimi primi de quibus constat per

83. Abreviaturas utilizadas: B. A. (Bachiller en Artes), B. Ph. (Bachiller en Filosofía), B. L. (Bachiller en Leyes), B. C. (Bachiller en Cánones), B. M. (Bachiller en Medicina), B. T. (Bachiller en Teología), Benef. (Beneficiado), Can. (Canónigo), Cl. (Clérigo), D. A. (Doctor en Artes), D. C. (Doctor en Cánones), D. Ph. (Doctor en Filosofía), D. L. (Doctor en Leyes), D. M. (Doctor en Medicina), D. T. (Doctor en Teología), Diác. (Diácono), Phil. (Filosofía), Fr. (Fray, sin otra indicación, religioso dominico), Gram. (Gramática), L. Ph. (Licenciado en Filosofía), L. L. (Licenciado en Leyes), L. C. (Licenciado en Cánones), L. M. (Licenciado en Medicina), L. T. (Licenciado en Teología), Nem. Disc. (Nemine discrepante), O. Carm. (Ordo Fratrum Beatissimae Mariae Virginis de Monte Carmelo), O. P. (Ordo Praedicatorum), Pbro. (Presbítero), Prof. (Profesor), Rdo. (Reverendo), SubDiác. (Subdiácono), Stud. (Estudiante), Theol. (Teología), U.I.D. (Utriusque Iuris Doctor, Doctor en ambos derechos). 
instrumentum apud Bernardum Coma auctoritatibus Apostolica et regia notarium publicum et dicta Universitatis secretarium recepta infra describantur ut in sequentibus foliis.

\begin{tabular}{|c|c|c|c|c|c|c|}
\hline NOMBRE & GRADO & FECHA & $\begin{array}{l}\text { RECTOR / } \\
\text { PADRINO }\end{array}$ & $\begin{array}{l}\text { EXAMINA- } \\
\text { DORES }\end{array}$ & TESTIGOS & $\begin{array}{l}\text { PROCE- } \\
\text { DENCIA }\end{array}$ \\
\hline $\begin{array}{c}\text { Pere } \\
\text { Escorcell }\end{array}$ & $\begin{array}{l}\text { B. T. } \\
\text { L. T. }\end{array}$ & $21-5-1701$ & $\begin{array}{l}\text { Fr. Tomàs } \\
\text { Bransi }\end{array}$ & $\begin{array}{c}\text { Fr. Pere M. Sama- } \\
\text { sada / Fr. Ramon } \\
\text { Bages }\end{array}$ & $\begin{array}{c}\text { Antoni } \\
\text { Pallarés / } \\
\text { Josep Vila, } \\
\text { de Solsona }\end{array}$ & O. P. \\
\hline $\begin{array}{l}\text { Domenec } \\
\text { Daniel }\end{array}$ & $\begin{array}{l}\text { B. T. } \\
\text { L. T. }\end{array}$ & $21-5-1701$ & $\begin{array}{l}\text { Fr. Tomàs } \\
\text { Bransi }\end{array}$ & $\begin{array}{c}\text { Fr. Pere M. Sama- } \\
\text { sada / Fr. Ramon } \\
\text { Bages }\end{array}$ & $\begin{array}{c}\text { Josep Vila } \\
\text { / Pere M. } \\
\text { Babies / } \\
\text { Domenec } \\
\text { Duran, de } \\
\text { Solsona }\end{array}$ & O. P. \\
\hline $\begin{array}{l}\text { Albert } \\
\text { Torres }\end{array}$ & $\begin{array}{l}\text { B. T. } \\
\text { L. T. }\end{array}$ & $21-5-1701$ & $\begin{array}{l}\text { Fr. Tomàs } \\
\text { Bransi }\end{array}$ & $\begin{array}{c}\text { Fr. Pere M. Sama- } \\
\text { sada / Fr. Ramon } \\
\text { Bages }\end{array}$ & $\begin{array}{l}\text { Josep Vila } \\
\text { / Pere M. } \\
\text { Babies / } \\
\text { Domenec } \\
\text { Duran }\end{array}$ & O. Carm. \\
\hline $\begin{array}{c}\text { Angel } \\
\text { Fàbregues }\end{array}$ & $\begin{array}{l}\text { B. T. } \\
\text { L. T. }\end{array}$ & $28-5-1701$ & $\begin{array}{l}\text { Fr. Tomàs } \\
\text { Bransi }\end{array}$ & $\begin{array}{c}\text { Fr. Pere M. Sama- } \\
\text { sada / Fr. Ramon } \\
\text { Bages }\end{array}$ & $\begin{array}{c}\text { Bernat } \\
\text { Tapia / Pere } \\
\text { M. Babies } \\
\text { (zapateros) }\end{array}$ & O. Carm. \\
\hline $\begin{array}{l}\text { Josep } \\
\text { Roca }\end{array}$ & $\begin{array}{l}\text { B. T. } \\
\text { L. T. }\end{array}$ & $28-5-1701$ & $\begin{array}{l}\text { Fr. Tomàs } \\
\text { Bransi }\end{array}$ & $\begin{array}{c}\text { Fr. Pere M. Sama- } \\
\text { sada / Fr. Ramon } \\
\text { Bages }\end{array}$ & $\begin{array}{c}\text { Bernat } \\
\text { Tapia / Pere } \\
\text { M. Babies }\end{array}$ & O. Carm. \\
\hline $\begin{array}{l}\text { Pere-Joan } \\
\text { Cardona }\end{array}$ & $\begin{array}{l}\text { B. T. } \\
\text { L. T. } \\
\text { D. T. } \\
\text { Nem. } \\
\text { Disc. }\end{array}$ & $\begin{array}{l}5-7-1701 \\
6-7-1701\end{array}$ & $\begin{array}{c}\text { Fr. Tomàs } \\
\text { Bransi / Fr. } \\
\text { Pere M. } \\
\text { Samasada }\end{array}$ & $\begin{array}{l}\text { Fr. Joan Tarda / Fr. } \\
\text { Ramon Bages }\end{array}$ & $\begin{array}{c}\text { Gabriel } \\
\text { Ferrer } \\
\text { (platero)/ } \\
\text { Bartolomé } \\
\text { Aguilar } \\
\text { (stud.)// } \\
\text { Josep Ferrer } \\
\text { / Josep Vilar } \\
\text { (profs. de } \\
\text { Phil.) }\end{array}$ & $\begin{array}{l}\text { Cl. de } \\
\text { Solsona }\end{array}$ \\
\hline $\begin{array}{l}\text { Bernat } \\
\text { Coma }\end{array}$ & $\begin{array}{l}\text { B. } \mathrm{Ph} \text {. } \\
\text { L. Ph. }\end{array}$ & $11-7-1701$ & $\begin{array}{l}\text { Fr. Tomàs } \\
\text { Bransi }\end{array}$ & $\begin{array}{c}\text { Fr. Pere M. Sama- } \\
\text { sada / Fr. Ramon } \\
\text { Bages }\end{array}$ & $\begin{array}{c}\text { Pere M. Ba- } \\
\text { bies / Pere } \\
\text { Comalada, } \\
\text { Pbro. D.T. } \\
\text { y Lector / } \\
\text { Victorià de } \\
\text { Bages (de } \\
\text { Vic) }\end{array}$ & $\begin{array}{c}\text { Cl. de } \\
\text { Manresa } \\
\text { (Dióc. de } \\
\text { Vic) }\end{array}$ \\
\hline $\begin{array}{l}\text { Josep } \\
\text { Enrich }\end{array}$ & $\begin{array}{l}\text { B. } \mathrm{Ph} \text {. } \\
\text { L. Ph. }\end{array}$ & $11-7-1701$ & $\begin{array}{l}\text { Fr. Tomàs } \\
\text { Bransi }\end{array}$ & $\begin{array}{c}\text { Fr. Pere M. Sama- } \\
\text { sada / Fr. Ramon } \\
\text { Bages }\end{array}$ & $\begin{array}{c}\text { Pere Co- } \\
\text { malada / } \\
\text { Victorià de } \\
\text { Bages }\end{array}$ & $\begin{array}{c}\text { Benef. de } \\
\text { la Cate- } \\
\text { dral de } \\
\text { Manresa }\end{array}$ \\
\hline
\end{tabular}




\begin{tabular}{|c|c|c|c|c|c|c|}
\hline NOMBRE & GRADO & FECHA & $\begin{array}{l}\text { RECTOR / } \\
\text { PADRINO }\end{array}$ & $\begin{array}{l}\text { EXAMINA- } \\
\text { DORES }\end{array}$ & TESTIGOS & $\begin{array}{l}\text { PROCE- } \\
\text { DENCIA }\end{array}$ \\
\hline $\begin{array}{l}\text { Miquel } \\
\text { Sastre }\end{array}$ & $\begin{array}{l}\text { B. } \mathrm{Ph} \text {. } \\
\text { L. } \mathrm{Ph} \text {. }\end{array}$ & $11-7-1701$ & $\begin{array}{l}\text { Fr. Tomàs } \\
\text { Bransi }\end{array}$ & $\begin{array}{c}\text { Fr. Pere M. Sama- } \\
\text { sada / Fr. Ramon } \\
\text { Bages }\end{array}$ & $\begin{array}{l}\text { Pere Co- } \\
\text { malada / } \\
\text { Victorià de } \\
\text { Bages }\end{array}$ & $\begin{array}{c}\text { Cl. de } \\
\text { Manresa }\end{array}$ \\
\hline $\begin{array}{l}\text { Joaquim } \\
\text { Llanes }\end{array}$ & $\begin{array}{l}\text { B. T. } \\
\text { L. T. }\end{array}$ & $11-7-1701$ & $\begin{array}{l}\text { Fr. Tomàs } \\
\text { Bransi }\end{array}$ & $\begin{array}{c}\text { Fr. Pere M. Sama- } \\
\text { sada / Fr. Ramon } \\
\text { Bages }\end{array}$ & $\begin{array}{c}\text { Pere Co- } \\
\text { malada / } \\
\text { Victorià de } \\
\text { Bages }\end{array}$ & $\begin{array}{l}\text { Can. de } \\
\text { Manresa }\end{array}$ \\
\hline $\begin{array}{l}\text { Urbicio } \\
\text { Closa }\end{array}$ & $\begin{array}{l}\text { B. T. } \\
\text { L. T. }\end{array}$ & $11-7-1701$ & $\begin{array}{c}\text { Fr. Tomàs } \\
\text { Bransi }\end{array}$ & $\begin{array}{c}\text { Fr. Pere M. Sama- } \\
\text { sada / Fr. Ramon } \\
\text { Bages }\end{array}$ & $\begin{array}{c}\text { Pere Co- } \\
\text { malada / } \\
\text { Victorià de } \\
\text { Bages }\end{array}$ & $\begin{array}{c}\text { Pbro. } \\
\text { Rector de } \\
\text { Salelles }\end{array}$ \\
\hline $\begin{array}{c}\text { Joan } \\
\text { Carreres }\end{array}$ & $\begin{array}{l}\text { B. T. } \\
\text { L. T. }\end{array}$ & $11-7-1701$ & $\begin{array}{l}\text { Fr. Tomàs } \\
\text { Bransi }\end{array}$ & $\begin{array}{c}\text { Fr. Pere M. Sama- } \\
\text { sada / Fr. Ramon } \\
\text { Bages }\end{array}$ & $\begin{array}{c}\text { Bernardo } \\
\text { Maleret / } \\
\text { Pere M. } \\
\text { Babies, } \\
\text { zapateros de } \\
\text { Manresa }\end{array}$ & $\begin{array}{c}\text { Cl. de } \\
\text { Manresa }\end{array}$ \\
\hline $\begin{array}{l}\text { Pere M. } \\
\text { Andreu }\end{array}$ & $\begin{array}{l}\text { B. T. } \\
\text { L. T. }\end{array}$ & $12-7-1701$ & $\begin{array}{l}\text { Fr. Tomàs } \\
\text { Bransi }\end{array}$ & $\begin{array}{c}\text { Fr. Pere M. Sama- } \\
\text { sada / Fr. Ramon } \\
\text { Bages }\end{array}$ & $\begin{array}{c}\text { Francisco } \\
\text { Soler / } \\
\text { Bernardino } \\
\text { Parent, Prof. } \\
\text { de Ph. de } \\
\text { Solsona }\end{array}$ & $\begin{array}{l}\text { Can. de } \\
\text { la Cate- } \\
\text { dral de } \\
\text { Solsona }\end{array}$ \\
\hline $\begin{array}{l}\text { Albert } \\
\text { Peres }\end{array}$ & $\begin{array}{l}\text { B. T. } \\
\text { L. T. }\end{array}$ & $13-7-1701$ & $\begin{array}{l}\text { Fr. Tomàs } \\
\text { Bransi }\end{array}$ & $\begin{array}{c}\text { Fr. Pere M. Sama- } \\
\text { sada / Fr. Ramon } \\
\text { Bages }\end{array}$ & $\begin{array}{c}\text { Cosme } \\
\text { Contestar } \\
\text { / Josep } \\
\text { Cansarell de } \\
\text { Solsona }\end{array}$ & O. Carm. \\
\hline $\begin{array}{l}\text { Francesc } \\
\text { Font }\end{array}$ & $\begin{array}{l}\text { B. T. } \\
\text { L. T. }\end{array}$ & $13-7-1701$ & $\begin{array}{l}\text { Fr. Tomàs } \\
\text { Bransi }\end{array}$ & $\begin{array}{c}\text { Fr. Pere M. Sama- } \\
\text { sada / Fr. Ramon } \\
\text { Bages }\end{array}$ & $\begin{array}{c}\text { Cosme } \\
\text { Contestar } \\
\text { / Josep } \\
\text { Cansarell de } \\
\text { Solsona }\end{array}$ & O. Carm. \\
\hline $\begin{array}{l}\text { Francesc } \\
\text { Vinyals }\end{array}$ & $\begin{array}{l}\text { B. } \mathrm{Ph} \text {. } \\
\text { L. } \mathrm{Ph} \text {. }\end{array}$ & $13-7-1701$ & $\begin{array}{l}\text { Fr. Tomàs } \\
\text { Bransi }\end{array}$ & $\begin{array}{c}\text { Fr. Pere M. Sama- } \\
\text { sada / Fr. Ramon } \\
\text { Bages }\end{array}$ & $\begin{array}{c}\text { Bernardo } \\
\text { Coma / } \\
\text { Jaime Puig, } \\
\text { manufac- } \\
\text { turero de } \\
\text { velos, de } \\
\text { Manresa }\end{array}$ & $\begin{array}{c}\text { Cl. de } \\
\text { Manresa }\end{array}$ \\
\hline $\begin{array}{l}\text { Pere Anto- } \\
\text { ni Carrió }\end{array}$ & $\begin{array}{l}\text { L. L. } \\
\text { D. L. } \\
\text { Nem. } \\
\text { Disc. }\end{array}$ & $19-8-1701$ & $\begin{array}{l}\text { Fr. Tomàs } \\
\text { Bransi }\end{array}$ & $\begin{array}{l}\text { Antoni Pallarés, } \\
\text { U.I.D. / Josep Vila }\end{array}$ & $\begin{array}{c}\text { Josep Vile- } \\
\text { lla / Pere M. } \\
\text { Babies } \\
\text { Josep Soler } \\
\text { / Gaspar } \\
\text { Pensi, profs. } \\
\text { de Filosofia }\end{array}$ & $\begin{array}{l}\text { De Ciuta- } \\
\text { della } \\
\text { (Menor- } \\
\text { ca) }\end{array}$ \\
\hline
\end{tabular}




\begin{tabular}{|c|c|c|c|c|c|c|}
\hline NOMBRE & GRADO & FECHA & $\begin{array}{l}\text { RECTOR / } \\
\text { PADRINO }\end{array}$ & $\begin{array}{l}\text { EXAMINA- } \\
\text { DORES }\end{array}$ & TESTIGOS & $\begin{array}{l}\text { PROCE- } \\
\text { DENCIA }\end{array}$ \\
\hline $\begin{array}{c}\text { Francisco } \\
\text { Tallades }\end{array}$ & $\begin{array}{l}\text { B. T. } \\
\text { L. T. } \\
\text { D. T. } \\
\text { Nem. } \\
\text { Disc. }\end{array}$ & $\begin{array}{l}\text { 16-9-1701 } \\
\text { Hora quin- } \\
\text { ta post }\end{array}$ & $\begin{array}{c}\text { Fr. Tomàs } \\
\text { Bransi / Fr. } \\
\text { Pere M. } \\
\text { Samasada }\end{array}$ & $\begin{array}{c}\text { Fr. Ramon Bages / } \\
\text { Miguel Parent }\end{array}$ & $\begin{array}{c}\text { Josep Vila- } \\
\text { dor, pbro. } \\
\text { de Solsona/ } \\
\text { Antonio } \\
\text { Mora, Diác. } \\
\text { de Artà, } \\
\text { Mallorca // } \\
\text { Pedro Juan } \\
\text { Cardona / } \\
\text { Pere M. Mi- } \\
\text { quel, profs. } \\
\text { de Phil. }\end{array}$ & $\begin{array}{l}\text { Diác. de } \\
\text { Campos, } \\
\text { Mallorca }\end{array}$ \\
\hline $\begin{array}{l}\text { Antonio } \\
\text { Ribot }\end{array}$ & $\begin{array}{l}\text { B. T. } \\
\text { L. T. } \\
\text { D. T. } \\
\text { Nem. } \\
\text { Disc. }\end{array}$ & $16-9-1701$ & $\begin{array}{c}\text { Fr. Tomàs } \\
\text { Bransi / Fr. } \\
\text { Pere M. } \\
\text { Samasada }\end{array}$ & $\begin{array}{l}\text { Tomás Torrents / } \\
\text { Ramon Bages }\end{array}$ & $\begin{array}{c}\text { Josep } \\
\text { Blanch de } \\
\text { la Corriu } \\
\text { / Antonio } \\
\text { Fornell de } \\
\text { la Selva, } \\
\text { studs. de } \\
\text { Solsona // } \\
\text { Miguel To- } \\
\text { rrents, Diác. } \\
\text { de Mallorca } \\
\text { / Gaspar } \\
\text { Pensi, stud. }\end{array}$ & $\begin{array}{c}\text { Diác. de } \\
\text { la Ciudad } \\
\text { de Ma- } \\
\text { llorca }\end{array}$ \\
\hline $\begin{array}{c}\text { Miguel } \\
\text { Carbonell }\end{array}$ & $\begin{array}{l}\text { B. T. } \\
\text { L. T. } \\
\\
\text { D. T. } \\
\text { Nem. } \\
\text { Disc. }\end{array}$ & $\begin{array}{l}16-4-1702 \\
17-4-1702\end{array}$ & $\begin{array}{l}\text { Fr. Diego } \\
\text { March } \\
\text { (Vice } \\
\text { rector)/ } \\
\text { Fr. Ramon } \\
\text { Bages }\end{array}$ & $\begin{array}{l}\text { Miguel Parent, } \\
\text { Can. / Juan Riu, } \\
\text { rector de Lladurs }\end{array}$ & $\begin{array}{l}\text { Rdo. Jeróni- } \\
\text { mo Jordana, } \\
\text { Diác. / Jo- } \\
\text { sep Blanch, } \\
\text { stud. }\end{array}$ & $\begin{array}{c}\text { Pbro. de } \\
\text { Ciutade- } \\
\text { lla, Me- } \\
\text { norca }\end{array}$ \\
\hline $\begin{array}{l}\text { Joan } \\
\text { Oliver }\end{array}$ & $\begin{array}{l}\text { B. T. } \\
\text { L. T. } \\
\\
\text { D. T. } \\
\text { Nem. } \\
\text { Disc. }\end{array}$ & $17-4-1702$ & $\begin{array}{l}\text { Fr. Diego } \\
\text { March } \\
\text { (Vice- } \\
\text { rector)/ } \\
\text { Fr. Ramon } \\
\text { Bages }\end{array}$ & $\begin{array}{l}\text { Miguel Parent, } \\
\text { Can. / Jaime Riu, } \\
\text { rector de Lladurs }\end{array}$ & $\begin{array}{c}\text { Antoni } \\
\text { Pallarés / } \\
\text { Josep Vilar, } \\
\text { Doctores de } \\
\text { Solsona }\end{array}$ & $\begin{array}{c}\text { Pbro. de } \\
\text { Ciutade- } \\
\text { lla, Me- } \\
\text { norca }\end{array}$ \\
\hline $\begin{array}{l}\text { Cosme } \\
\text { Albertí }\end{array}$ & $\begin{array}{l}\text { L. L. } \\
\\
\text { D. L. } \\
\text { Nem. } \\
\text { Disc. }\end{array}$ & $\begin{array}{l}24-4-1702 \\
25-4-1702\end{array}$ & $\begin{array}{c}\text { Fr. Pere } \\
\text { Samasada } \\
\text { (Vice- } \\
\text { rector)/ } \\
\text { Antoni } \\
\text { Pallarés }\end{array}$ & $\begin{array}{l}\text { Josep Llobet / } \\
\text { Josep Vila }\end{array}$ & $\begin{array}{c}\text { Mariano } \\
\text { Vidal, pbro. } \\
\text { / Pere M. } \\
\text { Babies, } \\
\text { zapatero }\end{array}$ & $\begin{array}{c}\text { De Aleor } \\
\text { (Alayor) } \\
\text { de Me- } \\
\text { norca }\end{array}$ \\
\hline
\end{tabular}




\begin{tabular}{|c|c|c|c|c|c|c|}
\hline NOMBRE & GRADO & FECHA & $\begin{array}{l}\text { RECTOR / } \\
\text { PADRINO }\end{array}$ & $\begin{array}{l}\text { EXAMINA- } \\
\text { DORES }\end{array}$ & TESTIGOS & $\begin{array}{l}\text { PROCE- } \\
\text { DENCIA }\end{array}$ \\
\hline $\begin{array}{l}\text { Antoni } \\
\text { Coma }\end{array}$ & $\begin{array}{l}\text { B. T. } \\
\text { L. T. } \\
\text { D. T. } \\
\text { Nem. } \\
\text { Disc. }\end{array}$ & $\begin{array}{l}2-5-1702 \\
3-5-1702\end{array}$ & $\begin{array}{l}\text { Fr. Pere } \\
\text { Samasa- } \\
\text { da (Vice } \\
\text { rector) / }\end{array}$ & $\begin{array}{c}\text { Ramon Bages / } \\
\text { Joan Riu, rector de } \\
\text { Lladurs }\end{array}$ & $\begin{array}{l}\text { Josep Va- } \\
\text { llonga / } \\
\text { Josep Vilar, } \\
\text { profs. de la } \\
\text { ciudad // } \\
\text { Antonio de } \\
\text { Boquet, D. } \\
\text { M. / Antoni } \\
\text { Pallarés, } \\
\text { U.I.D. }\end{array}$ & $\begin{array}{l}\text { Pbro. de } \\
\text { Solsona }\end{array}$ \\
\hline $\begin{array}{l}\text { Miquel } \\
\text { Ribot }\end{array}$ & $\begin{array}{l}\text { B. T. } \\
\text { L. T. } \\
\text { D. T. } \\
\text { Nem. } \\
\text { Disc. }\end{array}$ & $\begin{array}{l}1-6-1702 \\
2-6-1702\end{array}$ & $\begin{array}{c}\text { Fr. Tomàs } \\
\text { Bransi / Fr. } \\
\text { Pere M. } \\
\text { Samasada }\end{array}$ & $\begin{array}{l}\text { Fr. Diego March / } \\
\text { Fr. Ramon Bages }\end{array}$ & $\begin{array}{c}\text { Gaspar } \\
\text { Pensi / } \\
\text { Isidro Xam- } \\
\text { bo, profs. } \\
\text { de la ciudad } \\
\text { de Solsona } \\
\text { // Antoni } \\
\text { Pallarés, } \\
\text { U.I.D. / } \\
\text { Josep Vilar, } \\
\text { Doctores }\end{array}$ & $\begin{array}{c}\text { Pbro. } \\
\text { Benef. de } \\
\text { Gerona }\end{array}$ \\
\hline $\begin{array}{c}\text { Jacint } \\
\text { Cristofol }\end{array}$ & $\begin{array}{l}\text { B. A. } \\
\text { D. A. } \\
\text { Nem. } \\
\text { Disc. }\end{array}$ & 21-10-1702 & $\begin{array}{c}\text { Fr. Tomàs } \\
\text { Bransi / Fr. } \\
\text { Francisco } \\
\text { Pérez }\end{array}$ & $\begin{array}{c}\text { Fr. Pere M. Sama- } \\
\text { sada / Fr. Diego } \\
\text { March }\end{array}$ & $\begin{array}{l}\text { Jaime Vi- } \\
\text { lella / Joan } \\
\text { Farrer // An- } \\
\text { toni Palla- } \\
\text { rés, U.I.D. / } \\
\text { Josep Vilar, } \\
\text { Doctores }\end{array}$ & $\begin{array}{l}\text { Pbro. de } \\
\text { Grano- } \\
\text { llers Bar- } \\
\text { celona }\end{array}$ \\
\hline $\begin{array}{l}\text { Gabriel } \\
\text { Mir }\end{array}$ & $\begin{array}{l}\text { B. T. } \\
\text { L. T. } \\
\text { D. T. } \\
\text { Nem. } \\
\text { Disc. }\end{array}$ & $\begin{array}{l}29-10-1702 \\
30-10-1702\end{array}$ & $\begin{array}{l}\text { Fr. Tomàs } \\
\text { Bransi / Fr. } \\
\text { Francisco } \\
\text { Pérez }\end{array}$ & $\begin{array}{c}\text { Fr. Pere M. Sama- } \\
\text { sada / Fr. Diego } \\
\text { March }\end{array}$ & $\begin{array}{c}\text { Gabriel } \\
\text { Soler / } \\
\text { Josep Bo- } \\
\text { ziner, Prof. } \\
\text { de Ph.de la } \\
\text { ciudad. // } \\
\text { Antoni } \\
\text { Pallarés, } \\
\text { U.I.D. / } \\
\text { Josep Vilar, } \\
\text { Doctores }\end{array}$ & $\begin{array}{c}\text { Sub- } \\
\text { Diác. } \\
\text { de Maó, } \\
\text { Menorca }\end{array}$ \\
\hline $\begin{array}{l}\text { Llorenç } \\
\text { Salvá }\end{array}$ & $\begin{array}{l}\text { B. T. } \\
\text { L. T. } \\
\text { D. T. } \\
\text { Nem. } \\
\text { Disc. }\end{array}$ & $\begin{array}{l}7-12-1702 \\
8-12-1702\end{array}$ & $\begin{array}{c}\text { Fr. Tomàs } \\
\text { Bransi / Fr. } \\
\text { Pere M. } \\
\text { Samasada }\end{array}$ & $\begin{array}{l}\text { Fr. Diego March / } \\
\text { Fr. Francisco Pérez }\end{array}$ & $\begin{array}{l}\text { Antonio Pe- } \\
\text { gulla, pbro. } \\
\text { / Ramón } \\
\text { Nadal, prof. } \\
\text { de Phil. }\end{array}$ & $\begin{array}{l}\text { Rdo. de } \\
\text { la Ciudad } \\
\text { de Ma- } \\
\text { llorca }\end{array}$ \\
\hline
\end{tabular}




\begin{tabular}{|c|c|c|c|c|c|c|}
\hline NOMBRE & GRADO & FECHA & $\begin{array}{l}\text { RECTOR / } \\
\text { PADRINO }\end{array}$ & $\begin{array}{l}\text { EXAMINA- } \\
\text { DORES }\end{array}$ & TESTIGOS & $\begin{array}{l}\text { PROCE- } \\
\text { DENCIA }\end{array}$ \\
\hline $\begin{array}{l}\text { Jaime } \\
\text { Peregrí }\end{array}$ & $\begin{array}{l}\text { B. T. } \\
\text { L. T. } \\
\text { D. T. } \\
\text { Nem. } \\
\text { Disc. }\end{array}$ & $\begin{array}{l}13-3-1703 \\
14-3-1703\end{array}$ & $\begin{array}{c}\text { Fr. Tomàs } \\
\text { Bransi / }\end{array}$ & $\begin{array}{l}\text { Fr. Diego March / } \\
\text { Fr. Francisco Pérez }\end{array}$ & $\begin{array}{c}\text { Francisco } \\
\text { Salvador/ } \\
\text { Ramón Na- } \\
\text { dal, Prof. de } \\
\text { Ph. // Anto- } \\
\text { ni Pallarés, } \\
\text { U.I.D. / } \\
\text { Josep Vilar, } \\
\text { Doctor. }\end{array}$ & $\begin{array}{c}\text { O. Carm., } \\
\text { del Con- } \\
\text { vento de } \\
\text { la Ciudad } \\
\text { de Ma- } \\
\text { llorca }\end{array}$ \\
\hline $\begin{array}{l}\text { Jacinto } \\
\text { Caballol }\end{array}$ & $\begin{array}{l}\text { B. C. } \\
\text { L. C. }\end{array}$ & $25-3-1703$ & $\begin{array}{c}\text { Fr. Tomàs } \\
\text { Bransi / }\end{array}$ & $\begin{array}{l}\text { Antoni Pallares } \\
\text { / Josep Llobet / } \\
\text { Josep Vila }\end{array}$ & $\begin{array}{c}\text { Ramón } \\
\text { Nadal, Prof. } \\
\text { de Ph./ Pere } \\
\text { M. Bàbies, } \\
\text { zapatero }\end{array}$ & $\begin{array}{l}\text { Rdo. de } \\
\text { Oliana, } \\
\text { Diócesis } \\
\text { de Urgell }\end{array}$ \\
\hline $\begin{array}{l}\text { Josep } \\
\text { Llabrés }\end{array}$ & $\begin{array}{l}\text { B. T. } \\
\text { L. T. } \\
\text { D. T. } \\
\text { Nem. } \\
\text { Disc. }\end{array}$ & $\begin{array}{l}6-4-1703 \\
7-4-1703\end{array}$ & $\begin{array}{c}\text { Fr. Tomàs } \\
\text { Bransi / } \\
\text { Fr. Diego } \\
\text { March }\end{array}$ & $\begin{array}{l}\text { Fr. Francisco Pérez } \\
\text { / Josep Montella, } \\
\text { de Puigcerda }\end{array}$ & $\begin{array}{c}\text { Ramón } \\
\text { Nadal / } \\
\text { Francisco } \\
\text { Salvador, } \\
\text { Prof. de } \\
\text { Ph.// Antoni } \\
\text { Pallarés, } \\
\text { U.I.D./ } \\
\text { Josep Vilar, } \\
\text { Doctores }\end{array}$ & $\begin{array}{l}\text { Sub- } \\
\text { Diác. de } \\
\text { la Ciudad } \\
\text { de Ma- } \\
\text { llorca }\end{array}$ \\
\hline $\begin{array}{l}\text { Francisco } \\
\quad \text { Nuix }\end{array}$ & $\begin{array}{l}\text { B. T. } \\
\text { L. T. } \\
\text { D. T. }\end{array}$ & $\begin{array}{l}28-4-1703 \\
29-4-1703\end{array}$ & $\begin{array}{l}\text { Fr. Pere M. } \\
\text { Samasada } \\
\text { (Vice- } \\
\text { rector) / } \\
\text { Fr. Diego } \\
\text { March }\end{array}$ & $\begin{array}{l}\text { Fr. Francisco Pérez } \\
\text { / Pedro Juan Car- } \\
\text { dona, pbro. }\end{array}$ & $\begin{array}{l}\text { Antonio } \\
\text { Franch / } \\
\text { Josep Prats } \\
\text { i Ponsich, } \\
\text { Prof. de Ph. } \\
\text { de Solsona } \\
\text { // Antoni } \\
\text { Pallarés, } \\
\text { U.I.D./ } \\
\text { Josep Vilar, } \\
\text { Doctores }\end{array}$ & $\begin{array}{c}\text { Pbro. de } \\
\text { Cervera, } \\
\text { Diócesis } \\
\text { de Sol- } \\
\text { sona }\end{array}$ \\
\hline $\begin{array}{l}\text { Jerónimo } \\
\text { Riber }\end{array}$ & $\begin{array}{l}\text { B. T. } \\
\text { L. T. } \\
\\
\text { D. T. } \\
\text { Nem. } \\
\text { Disc. }\end{array}$ & $29-4-1703$ & $\begin{array}{l}\text { Fr. Pere } \\
\text { Samasa- } \\
\text { da (Vice } \\
\text { rector) / } \\
\text { Fr. Diego } \\
\text { March }\end{array}$ & $\begin{array}{l}\text { Fr. Francisco Pérez } \\
\text { / Pedro Juan Car- } \\
\text { dona, pbro. }\end{array}$ & $\begin{array}{c}\text { Josep Grau, } \\
\text { Decano de } \\
\text { la Catedral } \\
\text { de Solsona } \\
\text { / Esteban } \\
\text { Pons, D. M., } \\
\text { ciudadano } \\
\text { de Solsona }\end{array}$ & $\begin{array}{l}\text { Pbro. } \\
\text { Benefi- } \\
\text { ciado de } \\
\text { Solsona }\end{array}$ \\
\hline
\end{tabular}




\begin{tabular}{|c|c|c|c|c|c|c|}
\hline NOMBRE & GRADO & FECHA & $\begin{array}{l}\text { RECTOR / } \\
\text { PADRINO }\end{array}$ & $\begin{array}{l}\text { EXAMINA- } \\
\text { DORES }\end{array}$ & TESTIGOS & $\begin{array}{l}\text { PROCE- } \\
\text { DENCIA }\end{array}$ \\
\hline $\begin{array}{l}\text { Josep } \\
\text { Ribes }\end{array}$ & $\begin{array}{l}\text { B. T. } \\
\text { L. T. } \\
\text { D. T. } \\
\text { Nem. } \\
\text { Disc. }\end{array}$ & $12-5-1703$ & $\begin{array}{c}\text { Fr. Tomàs } \\
\text { Bransi / Fr. } \\
\text { Pere M. } \\
\text { Samasada }\end{array}$ & $\begin{array}{l}\text { Fr. Diego March / } \\
\text { Fr. Francisco Pérez }\end{array}$ & $\begin{array}{c}\text { Jaime Li- } \\
\text { sach, D. T., } \\
\text { ciudadano } \\
\text { de Barcelo- } \\
\text { na, residente } \\
\text { en Solsona } \\
\text { / Pere M. } \\
\text { Babies, } \\
\text { zapatero } \\
\text { // Antoni } \\
\text { Pallarés, } \\
\text { U.I.D. / } \\
\text { Josep Vilar, } \\
\text { Doctores }\end{array}$ & $\begin{array}{l}\text { Pbro. de } \\
\text { Manresa }\end{array}$ \\
\hline $\begin{array}{c}\text { Josep } \\
\text { Vallonga }\end{array}$ & $\begin{array}{l}\text { B. T. } \\
\text { L. T. } \\
\text { D. T. } \\
\text { Nem. } \\
\text { Disc. }\end{array}$ & $\begin{array}{l}30-6-1703 \\
1-7-1703\end{array}$ & $\begin{array}{c}\text { Fr. Tomàs } \\
\text { Bransi / Fr. } \\
\text { Pere M. } \\
\text { Samasada }\end{array}$ & $\begin{array}{l}\text { Fr. Diego March } \\
\text { / Fr. Francisco } \\
\text { Pérez. }\end{array}$ & $\begin{array}{c}\text { Francisco } \\
\text { Roure, Prof. } \\
\text { de T. / Pere } \\
\text { Martró, } \\
\text { stud. de } \\
\text { Gram. de } \\
\text { Solsona // } \\
\text { Francisco } \\
\text { Alsina Pbro. } \\
\text { / Jaime } \\
\text { Jordana, } \\
\text { artesano de } \\
\text { Solsona }\end{array}$ & $\begin{array}{l}\text { Cl. de } \\
\text { Solsona }\end{array}$ \\
\hline $\begin{array}{l}\text { Tomas } \\
\text { Villaró }\end{array}$ & $\begin{array}{l}\text { B. Ph. } \\
\text { L. Ph. } \\
\text { D. Ph. } \\
\text { Nem. } \\
\text { Disc. }\end{array}$ & $\begin{array}{l}1-7-1703 \\
2-7-1703\end{array}$ & $\begin{array}{c}\text { Fr. Tomàs } \\
\text { Bransi / Fr. } \\
\text { Francisco } \\
\text { Pérez }\end{array}$ & $\begin{array}{l}\text { Fr. Diego March / } \\
\text { Pere M. Samasada }\end{array}$ & $\begin{array}{c}\text { Francisco } \\
\text { Torres / } \\
\text { Juan Mar- } \\
\text { tró, Prof. } \\
\text { de Ph.de } \\
\text { Solsona. } \\
\text { Pedro Vile- } \\
\text { lla / Berna- } \\
\text { bé Colomes, } \\
\text { profs. de } \\
\text { Phil. }\end{array}$ & - \\
\hline $\begin{array}{l}\text { Pedro } \\
\text { Coranti }\end{array}$ & $\begin{array}{l}\text { B. T. } \\
\text { L. T. } \\
\text { D. T. } \\
\text { Nem. } \\
\text { Disc. }\end{array}$ & $\begin{array}{l}15-7-1703 \\
16-7-1703\end{array}$ & $\begin{array}{c}\text { Fr. Tomàs } \\
\text { Bransi / Fr. } \\
\text { Pere M. } \\
\text { Samasada }\end{array}$ & $\begin{array}{l}\text { Fr. Diego March } \\
\text { / Fr. Francisco } \\
\text { Pérez. }\end{array}$ & $\begin{array}{c}\text { Tomas } \\
\text { Pegullà / } \\
\text { Pedro Már- } \\
\text { tir Balbies, } \\
\text { zapateros } \\
\text { de Solsona } \\
\text { // Antoni } \\
\text { Pallarés, } \\
\text { U.I.D. / } \\
\text { Josep Vilar, } \\
\text { Doctores }\end{array}$ & $\begin{array}{l}\text { Cl. de } \\
\text { Maó, } \\
\text { Menorca }\end{array}$ \\
\hline
\end{tabular}




\begin{tabular}{|c|c|c|c|c|c|c|}
\hline NOMBRE & GRADO & FECHA & $\begin{array}{l}\text { RECTOR / } \\
\text { PADRINO }\end{array}$ & $\begin{array}{l}\text { EXAMINA- } \\
\text { DORES }\end{array}$ & TESTIGOS & $\begin{array}{l}\text { PROCE- } \\
\text { DENCIA }\end{array}$ \\
\hline $\begin{array}{l}\text { Pere } \\
\text { Tomàs } \\
\text { Catany }\end{array}$ & $\begin{array}{l}\text { B. T. } \\
\text { L. T. } \\
\text { D. T. } \\
\text { Nem. } \\
\text { Disc. }\end{array}$ & $\begin{array}{l}24-1-1704 \\
25-1-1704\end{array}$ & $\begin{array}{l}\text { Fr. Pere } \\
\text { M. Sama- } \\
\text { sada (Vice } \\
\text { rector) }\end{array}$ & $\begin{array}{l}\text { Fr. Diego March / } \\
\text { Fr. Francisco Pérez }\end{array}$ & $\begin{array}{c}\text { Josep Palla- } \\
\text { res / Ramón } \\
\text { Nadal // } \\
\text { Antonio de } \\
\text { Boquet, D. } \\
\text { M. / Antoni } \\
\text { Pallarés, } \\
\text { U.I.D. }\end{array}$ & O. Carm. \\
\hline $\begin{array}{l}\text { Josep } \\
\text { Cerch } \\
\text { (Serch) }\end{array}$ & $\begin{array}{l}\text { B. T. } \\
\text { L.T. } \\
\\
\text { D. T. } \\
\text { Nem. } \\
\text { Disc. }\end{array}$ & $\begin{array}{l}25-2-1704 \\
26-2-1704\end{array}$ & $\begin{array}{c}\text { Fr. Tomàs } \\
\text { Bransi / Fr. } \\
\text { Francisco } \\
\text { Pérez }\end{array}$ & $\begin{array}{l}\text { Jerónimo Riber / } \\
\text { Antonio Coma, } \\
\text { pbros. benef.s Doc- } \\
\text { tores de Solsona }\end{array}$ & $\begin{array}{c}\text { Josep Bala- } \\
\text { guer, estu- } \\
\text { diante / Juan } \\
\text { Torra, joven } \\
\text { agricultor } \\
\text { de Solsona } \\
\text { // Antoni } \\
\text { Pallarés, } \\
\text { U.I.D. / Mi- } \\
\text { guel Llobel, } \\
\text { Doctores. }\end{array}$ & $\begin{array}{c}\text { Pbro. } \\
\text { Rector } \\
\text { de Ozea, } \\
\text { Solsona }\end{array}$ \\
\hline $\begin{array}{l}\text { Rafael } \\
\text { Albertí }\end{array}$ & $\begin{array}{l}\text { B. L. } \\
\text { L. T. } \\
\text { D. L. } \\
\text { Nem. } \\
\text { Disc. }\end{array}$ & $\begin{array}{l}7-4-1704 \\
8-4-1704\end{array}$ & $\begin{array}{l}\text { Fr. Tomàs } \\
\text { Bransi / } \\
\text { Ramón } \\
\text { Vallonga }\end{array}$ & $\begin{array}{l}\text { Antoni Pallarés, } \\
\text { U.I.D. / Josep } \\
\text { Llobet, Doctores } \\
\text { de Solsona }\end{array}$ & $\begin{array}{c}\text { Jaime Mora } \\
\text { / Ramón } \\
\text { Nadal, Prof. } \\
\text { de Ph. de } \\
\text { Solsona } \\
\text { Jerónimo } \\
\text { Riber, Pbro } \\
\text { y D. T. / Es- } \\
\text { teban Pons, } \\
\text { D. M., de } \\
\text { Solsona }\end{array}$ & $\begin{array}{l}\text { De Ciu- } \\
\text { tadella } \\
\text { Menorca }\end{array}$ \\
\hline $\begin{array}{c}\text { Francisco } \\
\text { Carulla }\end{array}$ & $\begin{array}{l}\text { B. T } \\
\text { L. T. } \\
\text { D. T. } \\
\text { Nem. } \\
\text { Disc. }\end{array}$ & $29-4-1704$ & $\begin{array}{l}\text { Fr. Pere } \\
\text { Samasa- } \\
\text { da (Vice } \\
\text { rector) / Fr. } \\
\text { Francisco } \\
\text { Pérez }\end{array}$ & $\begin{array}{l}\text { Fr. Diego March } \\
\text { / Antonio Coma, } \\
\text { Pbro. de Solsona }\end{array}$ & $\begin{array}{c}\text { Esteban } \\
\text { Pons, } \\
\text { Doctor en } \\
\text { Medicina, } \\
\text { de Solsona } \\
\text { / Ramón } \\
\text { Nadal, Prof. } \\
\text { de Ph.de } \\
\text { Solsona. }\end{array}$ & $\begin{array}{c}\text { Vicario } \\
\text { perpetuo } \\
\text { de St. } \\
\text { Miguel } \\
\text { de Cas- } \\
\text { tellvell. } \\
\text { Solsona. }\end{array}$ \\
\hline $\begin{array}{c}\text { Juan } \\
\text { Antonio } \\
\text { Barceló }\end{array}$ & $\begin{array}{l}\text { B. T } \\
\text { L. T. } \\
\\
\text { D. T. } \\
\text { Nem. } \\
\text { Disc. }\end{array}$ & $25-6-1704$ & $\begin{array}{c}\text { Fr. Tomàs } \\
\text { Bransi } \\
\text { (Canciller) } \\
\text { / Fr. } \\
\text { Pere M. } \\
\text { Samasada }\end{array}$ & $\begin{array}{l}\text { Fr. Diego March } \\
\text { / Fr. Francisco } \\
\text { Pérez. }\end{array}$ & $\begin{array}{l}\text { Pere Mon- } \\
\text { taner / Juan } \\
\text { Riba, studs. }\end{array}$ & $\begin{array}{c}\text { O. Carm. } \\
\text { del Con- } \\
\text { vento de } \\
\text { la Ciudad } \\
\text { de Ma- } \\
\text { llorca }\end{array}$ \\
\hline
\end{tabular}




\begin{tabular}{|c|c|c|c|c|c|c|}
\hline NOMBRE & GRADO & FECHA & $\begin{array}{l}\text { RECTOR / } \\
\text { PADRINO }\end{array}$ & $\begin{array}{l}\text { EXAMINA- } \\
\text { DORES }\end{array}$ & TESTIGOS & $\begin{array}{l}\text { PROCE- } \\
\text { DENCIA }\end{array}$ \\
\hline $\begin{array}{l}\text { Ramón } \\
\text { Nadal }\end{array}$ & $\begin{array}{l}\text { L. Ph. } \\
\\
\text { D. Ph. } \\
\text { Nem. } \\
\text { Disc. }\end{array}$ & $11-7-1704$ & $\begin{array}{l}\text { Fr. Tomàs } \\
\text { Bransi } \\
\text { (Canci- } \\
\text { ller) / Fr. } \\
\text { Francisco } \\
\text { Pérez. }\end{array}$ & $\begin{array}{c}\text { Fr. Pere M. Sama- } \\
\text { sada / Fr. Diego } \\
\text { March }\end{array}$ & $\begin{array}{c}\text { Mariano So- } \\
\text { ler, cirujano } \\
\text { de Solsona } \\
\text { / Francisco } \\
\text { Soler, prof. } \\
\text { de Gram. } \\
\text { de Gosol. } \\
\text { // Antoni } \\
\text { Pallarés, } \\
\text { U.I.D. / Es- } \\
\text { teban Pons, } \\
\text { D. M. }\end{array}$ & $\begin{array}{l}\text { Prof. de } \\
\text { Ph. en } \\
\text { Guisona }\end{array}$ \\
\hline $\begin{array}{c}\text { Francesc } \\
\text { de Josa i } \\
\text { Agulló }\end{array}$ & D. C. & $13-9-1704$ & $\begin{array}{l}\text { Fr. Tomàs } \\
\text { Bransi } \\
\text { (Canciller) } \\
\text { / Mfco. } \\
\text { Antonio } \\
\text { Pallarés }\end{array}$ & $\begin{array}{c}\text { José Planes, Pbro. } \\
\text { y Can. de Tortosa / } \\
\text { Josep Llobet }\end{array}$ & $\begin{array}{c}\text { Miguel } \\
\text { Parent, } \\
\text { prebítero y } \\
\text { Can. de Sol- } \\
\text { sona / Jaime } \\
\text { Parent, Prof. } \\
\text { de Ph.de } \\
\text { Solsona. }\end{array}$ & $\begin{array}{c}\text { Arce- } \\
\text { diano de } \\
\text { Santa } \\
\text { María } \\
\text { del Mar } \\
\text { y Can. de } \\
\text { la Seo de } \\
\text { Barce- } \\
\text { lona }\end{array}$ \\
\hline $\begin{array}{c}\text { Juan } \\
\text { Lluch i } \\
\text { Azamor }\end{array}$ & $\begin{array}{l}\text { L. T. } \\
\text { D. T. }\end{array}$ & $13-12-1704$ & $\begin{array}{c}\text { Fr. Pere } \\
\text { Samasada } \\
\text { (Canciller) } \\
\text { / Fr. Diego } \\
\text { March }\end{array}$ & $\begin{array}{l}\text { Fr. Pere M. Monjo } \\
\text { / Félix Pallares, } \\
\text { Pbro. D. T. }\end{array}$ & $\begin{array}{l}\text { Domingo } \\
\text { Serch / } \\
\text { Josep Vilar, } \\
\text { studs. de } \\
\text { Solsona } \\
\text { // Josep } \\
\text { Llobet, D.T. } \\
\text { / Esteban } \\
\text { Pons, D. M. }\end{array}$ & $\begin{array}{l}\text { Pbro. de } \\
\text { Solsona }\end{array}$ \\
\hline $\begin{array}{c}\text { Juan } \\
\text { Ven- } \\
\text { dament }\end{array}$ & $\begin{array}{l}\text { L. Ph. } \\
\text { D. } \mathrm{Ph} \text {. }\end{array}$ & 19-12-1704 & $\begin{array}{l}\text { Fr. Pere } \\
\text { Samasada } \\
\text { (Canciller) } \\
\text { / Fr. Pere } \\
\text { M. Monjo }\end{array}$ & $\begin{array}{c}\text { Fr. Diego March } \\
\text { D.T. / Antonio } \\
\text { Coma, D.T., Pbro. } \\
\text { de Solsona }\end{array}$ & $\begin{array}{l}\text { Jerónimo } \\
\text { Arden, } \\
\text { Pbro. / } \\
\text { Bernabé } \\
\text { Colomes, } \\
\text { stud. en } \\
\text { Solsona. }\end{array}$ & $\begin{array}{l}\text { Pbro. de } \\
\text { Barce- } \\
\text { lona }\end{array}$ \\
\hline $\begin{array}{l}\text { Francisco } \\
\text { de Lli- } \\
\text { sachs }\end{array}$ & $\begin{array}{l}\text { L. Ph. } \\
\text { D. } \mathrm{Ph} \text {. }\end{array}$ & 19-12-1704 & $\begin{array}{c}\text { Fr. Pere } \\
\text { Samasada } \\
\text { (Vice- } \\
\text { rector) / } \\
\text { Fr. Pere M. } \\
\text { Monjo }\end{array}$ & $\begin{array}{c}\text { Fr. Diego March } \\
\text { D.T./ Antonio } \\
\text { Coma, D.T. }\end{array}$ & $\begin{array}{l}\text { Jerónimo } \\
\text { Arden, } \\
\text { Pbro. / } \\
\text { Bernabé } \\
\text { Colomes, } \\
\text { stud. en } \\
\text { Solsona. }\end{array}$ & $\begin{array}{l}\text { Pbro. de } \\
\text { Santpe- } \\
\text { dor }\end{array}$ \\
\hline
\end{tabular}




\begin{tabular}{|c|c|c|c|c|c|c|}
\hline NOMBRE & GRADO & FECHA & $\begin{array}{l}\text { RECTOR / } \\
\text { PADRINO }\end{array}$ & $\begin{array}{l}\text { EXAMINA- } \\
\text { DORES }\end{array}$ & TESTIGOS & $\begin{array}{l}\text { PROCE- } \\
\text { DENCIA }\end{array}$ \\
\hline $\begin{array}{l}\text { Alberto } \\
\text { Serralta }\end{array}$ & $\begin{array}{l}\text { L. T. } \\
\text { D. T. } \\
\text { Nem. } \\
\text { Disc. }\end{array}$ & $4-5-1705$ & $\begin{array}{l}\text { Fr. Pere M. } \\
\text { Samasada }\end{array}$ & $\begin{array}{l}\text { Fr. Pere M. Monjo } \\
\text { / Antonio Coma, } \\
\text { D.T. Pbro. Benef. } \\
\text { de Solsona }\end{array}$ & $\begin{array}{c}\text { Domingo } \\
\text { Serch, stud. } \\
\text { en Solsona } \\
\text { / Narciso } \\
\text { Ricort // } \\
\text { Esteban } \\
\text { Pons, D. } \\
\text { M. / Ramón } \\
\text { Vallonga, } \\
\text { D.T. }\end{array}$ & $\begin{array}{c}\text { O. Carm. } \\
\text { del Con- } \\
\text { vento de } \\
\text { la Ciudad } \\
\text { de Ma- } \\
\text { llorca }\end{array}$ \\
\hline $\begin{array}{l}\text { Luis } \\
\text { Pallarés }\end{array}$ & $\begin{array}{l}\text { L. T. } \\
\\
\text { D. T. } \\
\text { Nem. } \\
\text { Disc. }\end{array}$ & $\begin{array}{l}4-7-1705 \\
5-7-1705\end{array}$ & $\begin{array}{l}\text { Fr. Pere } \\
\text { Samasada } \\
\text { Canciller / } \\
\text { Fr. Diego } \\
\text { March, } \\
\text { D. T. }\end{array}$ & $\begin{array}{l}\text { Fr. Francisco Pérez } \\
\text { / Antonio Coma, } \\
\text { D.T. Pbro. Benef. } \\
\text { de Solsona }\end{array}$ & $\begin{array}{c}\text { Jerónimo } \\
\text { Arden, } \\
\text { Pbro./ } \\
\text { Bernabé } \\
\text { Colomes, } \\
\text { stud. en } \\
\text { Solsona // } \\
\text { Sebastián } \\
\text { Cortés / } \\
\text { Josep Martí, } \\
\text { estudiantes }\end{array}$ & $\begin{array}{l}\text { Cl. de } \\
\text { Solsona }\end{array}$ \\
\hline $\begin{array}{c}\text { Juan } \\
\text { Molinou }\end{array}$ & $\begin{array}{l}\text { L. T. } \\
\text { D. T. } \\
\text { Nem. } \\
\text { Disc. }\end{array}$ & $\begin{array}{l}2-9-1705 \\
3-9-1705\end{array}$ & $\begin{array}{c}\text { Fr. Pere } \\
\text { Samasada } \\
\text { Canciller/ } \\
\text { Fr. Diego } \\
\text { March }\end{array}$ & $\begin{array}{l}\text { Fr. Antoni Abad } \\
\text { / Fr. Pere Mártir } \\
\text { Monjo }\end{array}$ & $\begin{array}{c}\text { Domingo } \\
\text { Serch / Juan } \\
\text { Martro, } \\
\text { studs. en } \\
\text { Solsona } \\
\text { // Josep } \\
\text { Llobet D.T. } \\
\text { / Francisco } \\
\text { Vallonga, } \\
\text { D.T. }\end{array}$ & - \\
\hline $\begin{array}{l}\text { Pere Thur } \\
\text { (Tur) }\end{array}$ & $\begin{array}{l}\text { L. T. } \\
\\
\text { D. T. } \\
\text { Nem. } \\
\text { Disc. }\end{array}$ & $\begin{array}{l}30-7-1706 \\
31-7-1706\end{array}$ & $\begin{array}{l}\text { Fr. Pere } \\
\text { Samasada } \\
\text { Rector y } \\
\text { Canciller / } \\
\text { Fr. Diego } \\
\text { March }\end{array}$ & $\begin{array}{c}\text { Fr. Ramon Bages / } \\
\text { Antonio Coma, D. } \\
\text { T. Pbro. Benef. de } \\
\text { Solsona. }\end{array}$ & $\begin{array}{c}\text { Domingo } \\
\text { Grau, Deán } \\
\text { de Solsona/ } \\
\text { Domingo } \\
\text { Serch, stud. } \\
\text { en la ciudad } \\
\text { de Solsona } \\
\text { // Esteban } \\
\text { Pons, D. M. } \\
\text { / Domingo } \\
\text { Serch. }\end{array}$ & $\begin{array}{c}\text { Pbro. de } \\
\text { la villa } \\
\text { de Ibiza, } \\
\text { Diócesis } \\
\text { de Tarra- } \\
\text { gona }\end{array}$ \\
\hline $\begin{array}{l}\text { Ramón } \\
\text { Huguet }\end{array}$ & $\begin{array}{l}\text { L. T. } \\
\\
\text { D. T. } \\
\text { Nem. } \\
\text { Disc. }\end{array}$ & $29-10-1706$ & $\begin{array}{c}\text { Fr. Pere } \\
\text { Samasada } \\
\text { Rector y } \\
\text { Canciller/ } \\
\text { Fr. Diego } \\
\text { March }\end{array}$ & $\begin{array}{l}\text { Fr. Ramon Bages / } \\
\text { Fr. Pere M. Monjo }\end{array}$ & $\begin{array}{c}\text { Josep Pla- } \\
\text { nes, Can. / } \\
\text { Francisco } \\
\text { Carulla, } \\
\text { Pbro. de } \\
\text { Solsona }\end{array}$ & $\begin{array}{l}\text { Pbro. de } \\
\text { Cervera }\end{array}$ \\
\hline
\end{tabular}




\begin{tabular}{|c|c|c|c|c|c|c|}
\hline NOMBRE & GRADO & FECHA & $\begin{array}{l}\text { RECTOR / } \\
\text { PADRINO }\end{array}$ & $\begin{array}{l}\text { EXAMINA- } \\
\text { DORES }\end{array}$ & TESTIGOS & $\begin{array}{l}\text { PROCE- } \\
\text { DENCIA }\end{array}$ \\
\hline $\begin{array}{c}\text { Marco } \\
\text { Antonio } \\
\text { Capdevila }\end{array}$ & $\begin{array}{l}\text { D. T. } \\
\text { Nem. } \\
\text { Disc. }\end{array}$ & 24-11-1706 & $\begin{array}{l}\text { Fr. Pere M. } \\
\text { Samasada } \\
\text { Rector / } \\
\text { Fr. Diego } \\
\text { March }\end{array}$ & $\begin{array}{l}\text { Fr. Ramon Bages / } \\
\text { Fr. Pere M. Monjo }\end{array}$ & $\begin{array}{l}\text { Bernardo } \\
\text { Tapia, cor- } \\
\text { delero / Fe- } \\
\text { lix Beltran, } \\
\text { agricultor // } \\
\text { Juan Martro } \\
\text { / Josep Bo- } \\
\text { cines, studs. } \\
\text { en Solsona. }\end{array}$ & $\begin{array}{l}\text { Pbro. de } \\
\text { Talarn }\end{array}$ \\
\hline $\begin{array}{l}\text { Onofre } \\
\text { Planes }\end{array}$ & $\begin{array}{l}\text { L. T. } \\
\text { D. T. } \\
\text { Nem. } \\
\text { Disc. }\end{array}$ & $\begin{array}{l}11-2-1707 \\
12-2-1707\end{array}$ & $\begin{array}{l}\text { Fr. Pere M. } \\
\text { Samasada/ } \\
\text { Fr. Diego } \\
\text { March }\end{array}$ & $\begin{array}{l}\text { Fr. Ramon Bages / } \\
\text { Fr. Pere M. Monjo }\end{array}$ & $\begin{array}{c}\text { Jaime Giró, } \\
\text { benef., Ma- } \\
\text { riano Soler, } \\
\text { cirujano } \\
\text { ambos de } \\
\text { Solsona // } \\
\text { Miguel } \\
\text { Parent/ } \\
\text { Antonio } \\
\text { del Graner, } \\
\text { profs. de } \\
\text { Theol. }\end{array}$ & $\begin{array}{l}\text { Pbro. } \\
\text { de Vall- } \\
\text { fogona } \\
\text { (Diócesis } \\
\text { de Vic) }\end{array}$ \\
\hline $\begin{array}{c}\text { Josep } \\
\text { Taltavull }\end{array}$ & $\begin{array}{l}\text { D. T. } \\
\text { Nem. } \\
\text { Disc. }\end{array}$ & $\begin{array}{l}4-4-1707 \\
5-4-1707\end{array}$ & $\begin{array}{l}\text { Fr. Ramon } \\
\text { Bages, } \\
\text { Vice-rector } \\
\text { / Fr. Pere } \\
\text { M. Monjo }\end{array}$ & $\begin{array}{c}\text { Antonio Colomes, } \\
\text { benef. eb la Ca- } \\
\text { tedral de Solsona } \\
\text { / Luis Pallares, } \\
\text { Doctor. }\end{array}$ & $\begin{array}{c}\text { Pedro Escu- } \\
\text { bet stud. de } \\
\text { Gramatica } \\
\text { de Berga / } \\
\text { Jaime Can- } \\
\text { tons, stud. } \\
\text { de Theol. } \\
\text { // Josep } \\
\text { Llobet D.T. } \\
\text { / Francisco } \\
\text { Serch, D. } \\
\text { M. }\end{array}$ & $\begin{array}{l}\text { Diác. de } \\
\text { Ciutade- } \\
\text { lla Me- } \\
\text { norca }\end{array}$ \\
\hline $\begin{array}{c}\text { Josep } \\
\text { Prats i } \\
\text { Ponsich }\end{array}$ & $\begin{array}{l}\text { D. T. } \\
\text { Nem. } \\
\text { Disc. }\end{array}$ & $\begin{array}{l}10-6-1707 \\
11-6-1707\end{array}$ & $\begin{array}{l}\text { Fr. Pere } \\
\text { M. Sa- } \\
\text { masada / } \\
\text { Fr. Diego } \\
\text { March }\end{array}$ & $\begin{array}{c}\text { Fr. Ramon Bages, } \\
\text { / Pedro Mártir } \\
\text { Monjo }\end{array}$ & $\begin{array}{c}\text { Jerónimo } \\
\text { Cerver, } \\
\text { prof. de } \\
\text { Phil./ Tomás } \\
\text { Pegulla, } \\
\text { cordelero // } \\
\text { Domingo } \\
\text { Serch / Juan } \\
\text { Martro, } \\
\text { studs. en } \\
\text { Solsona }\end{array}$ & $\begin{array}{c}\text { Cl. de } \\
\text { Barce- } \\
\text { lona }\end{array}$ \\
\hline
\end{tabular}




\begin{tabular}{|c|c|c|c|c|c|c|}
\hline NOMBRE & GRADO & FECHA & $\begin{array}{l}\text { RECTOR / } \\
\text { PADRINO }\end{array}$ & $\begin{array}{l}\text { EXAMINA- } \\
\text { DORES }\end{array}$ & TESTIGOS & $\begin{array}{l}\text { PROCE- } \\
\text { DENCIA }\end{array}$ \\
\hline $\begin{array}{c}\text { Josep } \\
\text { Botines }\end{array}$ & $\begin{array}{l}\text { D. T. } \\
\text { Nem. } \\
\text { Disc. }\end{array}$ & $\begin{array}{l}2-7-1707 \\
3-7-1707\end{array}$ & $\begin{array}{c}\text { Fr. Pere M. } \\
\text { Samasada/ } \\
\text { Fr. } \\
\text { Ramon } \\
\text { Bages }\end{array}$ & $\begin{array}{l}\text { Fr. Diego March/ } \\
\text { Fr. Pere M. Monjo }\end{array}$ & $\begin{array}{c}\text { Francisco } \\
\text { Llaneres, } \\
\text { stud. T. / } \\
\text { Pedro Mon- } \\
\text { taner, stud. } \\
\text { de Gram. // } \\
\text { Josep Vile- } \\
\text { lla, sastre } \\
\text { / Josep } \\
\text { Cantarell, } \\
\text { curtidor y } \\
\text { Mauricio } \\
\text { Illa, escri- } \\
\text { bano (susti- } \\
\text { tuto). }\end{array}$ & $\begin{array}{l}\text { Cl. de } \\
\text { Solsona }\end{array}$ \\
\hline $\begin{array}{l}\text { Antonio } \\
\text { Vila }\end{array}$ & $\begin{array}{l}\text { L. Ph. } \\
\text { D. Ph. } \\
\text { Nem. } \\
\text { Disc. }\end{array}$ & $28-2-1708$ & $\begin{array}{c}\text { Fr. Pere } \\
\text { Samasada/ } \\
\text { Fr. Pere M. } \\
\text { Monjo }\end{array}$ & $\begin{array}{l}\text { Fr. Diego March/ } \\
\text { Fr. Ramon Bages }\end{array}$ & $\begin{array}{c}\text { Tomás } \\
\text { Pegulla/ } \\
\text { Celedonio } \\
\text { Trapasso, } \\
\text { zapateros. }\end{array}$ & $\begin{array}{l}\text { Cl. de } \\
\text { Solsona }\end{array}$ \\
\hline $\begin{array}{l}\text { Marco } \\
\text { Olives }\end{array}$ & $\begin{array}{l}\text { L. T. } \\
\text { D. T. } \\
\text { Nem. } \\
\text { Disc. }\end{array}$ & $18-5-1708$ & $\begin{array}{c}\text { Fr. Pere } \\
\text { Samasada/ } \\
\text { Fr. Ramon } \\
\text { Bages }\end{array}$ & $\begin{array}{l}\text { Fr. Diego March/ } \\
\text { Fr. Pere M. Monjo }\end{array}$ & $\begin{array}{l}\text { Josep Ca- } \\
\text { samartina, } \\
\text { Can. / Jaime } \\
\text { Giró, benef., } \\
\text { ambos de } \\
\text { Solsona }\end{array}$ & $\begin{array}{l}\text { Diác. de } \\
\text { Ciutade- } \\
\text { lla Me- } \\
\text { norca }\end{array}$ \\
\hline $\begin{array}{l}\text { Francisco } \\
\text { Aymerich }\end{array}$ & $\begin{array}{l}\text { L. T. } \\
\text { D. T. } \\
\text { Nem. } \\
\text { Disc. }\end{array}$ & $\begin{array}{c}31-5-1708 \\
1-6-1708\end{array}$ & $\begin{array}{c}\text { Fr. Pere } \\
\text { Samasada/ } \\
\text { Fr. Pere M. } \\
\text { Monjo }\end{array}$ & $\begin{array}{l}\text { Fr. Diego March/ } \\
\text { Fr. Ramon Bages }\end{array}$ & $\begin{array}{l}\text { Josep Grau } \\
\text { / Antoni } \\
\text { del Graner, } \\
\text { profs. de } \\
\text { Theol. // Jo- } \\
\text { sep Llobet / } \\
\text { Josep Grau, } \\
\text { profs. de } \\
\text { Theol. }\end{array}$ & $\begin{array}{c}\text { Pbro. de } \\
\text { Ribes, } \\
\text { Urgell }\end{array}$ \\
\hline $\begin{array}{l}\text { Isidro } \\
\text { Font }\end{array}$ & $\begin{array}{l}\text { L. T. } \\
\text { D. T. } \\
\text { Nem. } \\
\text { Disc. }\end{array}$ & $\begin{array}{l}21-6-1708 \\
22-6-1708\end{array}$ & $\begin{array}{c}\text { Fr. Pere M. } \\
\text { Samasada/ } \\
\text { Fr. Diego } \\
\text { March }\end{array}$ & $\begin{array}{l}\text { Fr. Ramon Bages, / } \\
\text { Fr. Pere M. Monjo }\end{array}$ & $\begin{array}{c}\text { Josep Ruet } \\
\text { / Josep } \\
\text { Morrolius, } \\
\text { profs. de } \\
\text { Cervera // } \\
\text { Antonio } \\
\text { Bordons, } \\
\text { Gabriel } \\
\text { Vilaró, } \\
\text { profesores. }\end{array}$ & $\begin{array}{l}\text { Cl. de } \\
\text { Solsona }\end{array}$ \\
\hline $\begin{array}{l}\text { Miquel } \\
\text { Dameto }\end{array}$ & $\begin{array}{l}\text { L. T. } \\
\text { D. T. } \\
\text { Nem. } \\
\text { Disc. }\end{array}$ & $31-10-1708$ & $\begin{array}{c}\text { Fr. Pere M. } \\
\text { Samasada/ } \\
\text { Fr. Pere M. } \\
\text { Monjo }\end{array}$ & $\begin{array}{l}\text { Fr. Diego March/ } \\
\text { Tomás Llanes }\end{array}$ & $\begin{array}{c}\text { Jerónimo } \\
\text { Arden/ } \\
\text { Francisco } \\
\text { Llaneres, } \\
\text { profesores. }\end{array}$ & $\begin{array}{l}\text { Rdo. de } \\
\text { la Ciudad } \\
\text { de Palma } \\
\text { de Ma- } \\
\text { llorca }\end{array}$ \\
\hline
\end{tabular}




\begin{tabular}{|c|c|c|c|c|c|c|}
\hline NOMBRE & GRADO & FECHA & $\begin{array}{l}\text { RECTOR / } \\
\text { PADRINO }\end{array}$ & $\begin{array}{l}\text { EXAMINA- } \\
\text { DORES }\end{array}$ & TESTIGOS & $\begin{array}{l}\text { PROCE- } \\
\text { DENCIA }\end{array}$ \\
\hline $\begin{array}{l}\text { Tomàs } \\
\text { Llanés }\end{array}$ & $\begin{array}{l}\text { L. T. } \\
\text { D. T. } \\
\text { Nem. } \\
\text { Disc. }\end{array}$ & $31-10-1708$ & $\begin{array}{l}\text { Fr. Pere M. } \\
\text { Samasada }\end{array}$ & $\begin{array}{l}\text { Fr. Diego March / } \\
\text { Fr. Pere M. Monjo }\end{array}$ & $\begin{array}{l}\text { Jerónimo } \\
\text { Arden/ } \\
\text { Francisco } \\
\text { Llaneres, } \\
\text { profesores }\end{array}$ & O. P. \\
\hline $\begin{array}{l}\text { Miquel } \\
\text { Mulet }\end{array}$ & $\begin{array}{l}\text { L. M. } \\
\text { D. M. } \\
\text { Nem. } \\
\text { Disc. }\end{array}$ & 30-1-1709 & $\begin{array}{l}\text { Fr. Diego } \\
\text { March, } \\
\text { Vice-rector } \\
\text { / Francisco } \\
\text { Cerch }\end{array}$ & $\begin{array}{c}\text { Bernardino Parent, } \\
\text { D. M./ Carlos } \\
\text { Reygada, D. M. }\end{array}$ & $\begin{array}{c}\text { Josep } \\
\text { Vallonga/ } \\
\text { Isidro Font, } \\
\text { Clers. // } \\
\text { Jerónimo } \\
\text { Riber, Pbro. } \\
\text { / Antoni } \\
\text { Pallarés, } \\
\text { U.I.D. }\end{array}$ & $\begin{array}{c}\text { De la } \\
\text { villa de } \\
\text { Algaida, } \\
\text { Mallorca }\end{array}$ \\
\hline $\begin{array}{l}\text { Francisco } \\
\text { Melià }\end{array}$ & $\begin{array}{l}\text { L. T. } \\
\text { D. T. } \\
\text { Nem. } \\
\text { Disc. }\end{array}$ & $\begin{array}{l}17-5-1709 \\
18-5-1709\end{array}$ & $\begin{array}{l}\text { Fr. Pere M. } \\
\text { Samasada- } \\
\text { Vice-rector } \\
\text { / Fr. Pere } \\
\text { M. Monjo }\end{array}$ & $\begin{array}{c}\text { Fr. Ramon Bages/ } \\
\text { Fr. Tomás Llanés, } \\
\text { Doctores }\end{array}$ & $\begin{array}{l}\text { Josep Pujol, } \\
\text { subDiác. / } \\
\text { Jaime Can- } \\
\text { tons, Cler. }\end{array}$ & O. Carm. \\
\hline $\begin{array}{l}\text { Francisco } \\
\text { de Anus } \\
\text { (Danús) }\end{array}$ & $\begin{array}{l}\text { L. T. } \\
\text { D. T. } \\
\text { Nem. } \\
\text { Disc. }\end{array}$ & $18-6-1709$ & $\begin{array}{c}\text { Fr. Pere M. } \\
\text { Samasada- } \\
\text { Vice-rector } \\
\text { / Fr. Tomás } \\
\text { Llanés }\end{array}$ & $\begin{array}{c}\text { Fr. Ramon Bages/ } \\
\text { Pere M. Monjo, } \\
\text { Doctores cole- } \\
\text { giales. }\end{array}$ & $\begin{array}{c}\text { Isidro Font, } \\
\text { Cler., D. T. } \\
\text { / Narciso } \\
\text { Record, } \\
\text { tejedor de } \\
\text { paños, de } \\
\text { Solsona // } \\
\text { Antoni } \\
\text { Pallarés, } \\
\text { U.I.D. / } \\
\text { Isidro Font, } \\
\text { ambos D. T. } \\
\text { de Solsona }\end{array}$ & $\begin{array}{l}\text { Cl. de } \\
\text { Llucma- } \\
\text { jor, } \\
\text { Mallorca }\end{array}$ \\
\hline $\begin{array}{l}\text { Francisco } \\
\text { Llaneres }\end{array}$ & $\begin{array}{l}\text { L. T. } \\
\text { D. T. } \\
\text { Nem. } \\
\text { Disc. }\end{array}$ & $\begin{array}{l}6-7-1709 \\
6-7-1709\end{array}$ & $\begin{array}{c}\text { Fr. Pere } \\
\text { Samasada } \\
\text { Vice-rector } \\
\text { / Fr. Ra- } \\
\text { mon Bages }\end{array}$ & $\begin{array}{l}\text { Fr. Pere M. Monjo } \\
\text { / Fr. Tomás Llanés, } \\
\text { Doctores. }\end{array}$ & $\begin{array}{c}\text { Domingo } \\
\text { Serch / Jai- } \\
\text { me Cantons, } \\
\text { estudian- } \\
\text { tes // } \\
\text { Josep Grau / } \\
\text { Domingo } \\
\text { Cerch, } \\
\text { studs. de } \\
\text { Theol. }\end{array}$ & $\begin{array}{l}\text { Cl. de } \\
\text { Solsona }\end{array}$ \\
\hline
\end{tabular}




\begin{tabular}{|c|c|c|c|c|c|c|}
\hline NOMBRE & GRADO & FECHA & $\begin{array}{l}\text { RECTOR / } \\
\text { PADRINO }\end{array}$ & $\begin{array}{l}\text { EXAMINA- } \\
\text { DORES }\end{array}$ & TESTIGOS & $\begin{array}{l}\text { PROCE- } \\
\text { DENCIA }\end{array}$ \\
\hline $\begin{array}{l}\text { Josep } \\
\text { Pujol }\end{array}$ & $\begin{array}{l}\text { D. T. } \\
\text { Nem. } \\
\text { Disc. }\end{array}$ & $\begin{array}{l}12-7-1709 \\
13-7-1709\end{array}$ & $\begin{array}{l}\text { Fr. Pere } \\
\text { Samasada- } \\
\text { Vice-rector } \\
\text { / Fr. Pere } \\
\text { M. Monjo }\end{array}$ & $\begin{array}{l}\text { Fr. Pere M. Monjo } \\
\text { / Fr. Tomàs Llanés, } \\
\text { Doctores }\end{array}$ & $\begin{array}{c}\text { Josep Rovi- } \\
\text { ra de Solso- } \\
\text { na/ Torrent, } \\
\text { stud. de } \\
\text { Pinell // An- } \\
\text { toni Palla- } \\
\text { rés, U.I.D. } \\
\text { / Francisco } \\
\text { Font, D. } \\
\text { Ph., prof. de } \\
\text { Solsona }\end{array}$ & $\begin{array}{l}\text { Pbro. de } \\
\text { Solsona }\end{array}$ \\
\hline $\begin{array}{l}\text { Gabriel } \\
\text { Dalmau }\end{array}$ & $\begin{array}{l}\text { L. T. } \\
\text { D. T. } \\
\text { Nem. } \\
\text { Disc. }\end{array}$ & 25-11-1709 & $\begin{array}{c}\text { Fr. Pere } \\
\text { Samasada } \\
\text { Vice-rector } \\
\text { / Fr. Ra- } \\
\text { mon Bages }\end{array}$ & $\begin{array}{l}\text { Fr. Pere M. Monjo } \\
\text { / Fr. Tomás Llanés, } \\
\text { Doctores }\end{array}$ & $\begin{array}{c}\text { Miguel } \\
\text { Parent, } \\
\text { D.T., Can. / } \\
\text { Pedro Juan } \\
\text { Cardona, D. } \\
\text { T., benef. } \\
\text { de Solsona } \\
\text { // Antoni } \\
\text { Pallarés, } \\
\text { U.I.D. / } \\
\text { Pere M. Irla, } \\
\text { estudiante. }\end{array}$ & O. P. \\
\hline $\begin{array}{l}\text { Francisco } \\
\text { Andreu y } \\
\text { de Miguel }\end{array}$ & $\begin{array}{l}\text { D. T. } \\
\text { Nem. } \\
\text { Disc. }\end{array}$ & 25-11-1709 & $\begin{array}{c}\text { Fr. Pere M. } \\
\text { Samasada } \\
\text { Vicerector } \\
\text { /Fr. Ramon } \\
\text { Bages }\end{array}$ & $\begin{array}{l}\text { Fr. Pere M. Monjo } \\
\text { / Fr. Tomás Llanés }\end{array}$ & $\begin{array}{c}\text { Miguel } \\
\text { Parent, Can. } \\
\text { / Pedro Juan } \\
\text { Cardona, } \\
\text { benef. en la } \\
\text { Catedral de } \\
\text { Solsona // } \\
\text { Luis Palla- } \\
\text { res, D.T. / } \\
\text { Pedro Rovi- } \\
\text { ra, cirujano }\end{array}$ & $\begin{array}{c}\text { Cl. de } \\
\text { Solsona } \\
\text { y Prof. de } \\
\text { Theol. }\end{array}$ \\
\hline $\begin{array}{l}\text { Magí } \\
\text { Solans }\end{array}$ & $\begin{array}{l}\text { D. T. } \\
\text { Nem. } \\
\text { Disc. }\end{array}$ & 16-12-1709 & $\begin{array}{c}\text { Fr. Gabriel } \\
\text { Dalmau / } \\
\text { Fr. Ramon } \\
\text { Bages }\end{array}$ & $\begin{array}{c}\text { Fr. Pere M. Sama- } \\
\text { sada / Fr. Pere M. } \\
\text { Monjo }\end{array}$ & $\begin{array}{c}\text { Joan Martro } \\
\text { / Ramon } \\
\text { Manonelles, } \\
\text { profs. de } \\
\text { Theol. // } \\
\text { Mfco. Anto- } \\
\text { ni Pallarés, } \\
\text { U.I.D. / } \\
\text { Joan Mar- } \\
\text { tró, Prof. de } \\
\text { Theol. en } \\
\text { Solsona }\end{array}$ & $\begin{array}{c}\text { Cl. de } \\
\text { Oliana, } \\
\text { Diócesis } \\
\text { de Urgell }\end{array}$ \\
\hline
\end{tabular}




\begin{tabular}{|c|c|c|c|c|c|c|}
\hline NOMBRE & GRADO & FECHA & $\begin{array}{l}\text { RECTOR / } \\
\text { PADRINO }\end{array}$ & $\begin{array}{l}\text { EXAMINA- } \\
\text { DORES }\end{array}$ & TESTIGOS & $\begin{array}{l}\text { PROCE- } \\
\text { DENCIA }\end{array}$ \\
\hline $\begin{array}{l}\text { Bernat } \\
\text { Coma }\end{array}$ & $\begin{array}{l}\text { L. T. } \\
\text { D. T. } \\
\text { Nem. } \\
\text { Disc. }\end{array}$ & $\begin{array}{l}25-1-1710 \\
26-1-1710\end{array}$ & $\begin{array}{l}\text { Fr. Gabriel } \\
\text { Dalmau / } \\
\text { Fr. Pere M. } \\
\text { Samasada }\end{array}$ & $\begin{array}{l}\text { Fr. Pere M. Monjo } \\
\text { / Fr. Tomás Llanés }\end{array}$ & $\begin{array}{c}\text { Bernardo } \\
\text { Tapia, } \\
\text { zapatero } \\
\text { de Solsona } \\
\text { / Isidoro } \\
\text { Subirano, } \\
\text { ciudadano } \\
\text { de Manresa } \\
\text { // Antoni } \\
\text { Pallarés, } \\
\text { U.I.D. / } \\
\text { Antoni } \\
\text { Font, stud. } \\
\text { de Solsona }\end{array}$ & $\begin{array}{c}\text { Cl. de } \\
\text { Manresa, } \\
\text { diócesis } \\
\text { de Vic }\end{array}$ \\
\hline Juan Pons & $\begin{array}{l}\text { L. M. } \\
\text { D. M. } \\
\text { Nem. } \\
\text { Disc. }\end{array}$ & $\begin{array}{l}4-4-1710 \\
5-4-1710\end{array}$ & $\begin{array}{l}\text { Fr. Gabriel } \\
\text { Dalmau / }\end{array}$ & $\begin{array}{l}\text { Francisco Crech } \\
\text { D. M. / Bernardino } \\
\text { Parent, D. M. }\end{array}$ & $\begin{array}{c}\text { Juan Patus, } \\
\text { ciudadano } \\
\text { de Barce- } \\
\text { lona/ Josep } \\
\text { Miró, stud. } \\
\text { en Solsona } \\
\text { // Antoni } \\
\text { Pallares, } \\
\text { U.I.D. / } \\
\text { Francisco } \\
\text { Font, stud. }\end{array}$ & $\begin{array}{l}\text { De Bi- } \\
\text { nissalem- } \\
\text { Mallorca, } \\
\text { B. M. }\end{array}$ \\
\hline $\begin{array}{l}\text { Jaime } \\
\text { Argullol }\end{array}$ & $\begin{array}{l}\text { L. T. } \\
\text { D. T. } \\
\text { Nem. } \\
\text { Disc. }\end{array}$ & $\begin{array}{l}2-5-1710 \\
3-5-1710\end{array}$ & $\begin{array}{l}\text { Fr. Pere M. } \\
\text { Samasada- } \\
\text { Vice-rector }\end{array}$ & $\begin{array}{c}\text { Fr. Ramon Bages/ } \\
\text { Fr. Tomás Llanés, } \\
\text { Doctores }\end{array}$ & $\begin{array}{c}\text { Bernardo } \\
\text { Tapia, zapa- } \\
\text { tero / Josep } \\
\text { Cases, stud. } \\
\text { en Solsona } \\
\text { // Ramón } \\
\text { Borrell, } \\
\text { Diác. / Fco. } \\
\text { Font, stud. }\end{array}$ & $\begin{array}{l}\text { Pbro. y } \\
\text { Benef. de } \\
\text { Calaf }\end{array}$ \\
\hline $\begin{array}{l}\text { Juan } \\
\text { Bautista } \\
\text { Suau }\end{array}$ & $\begin{array}{l}\text { L. T. } \\
\text { D. T. } \\
\text { Nem. } \\
\text { Disc. }\end{array}$ & $\begin{array}{l}21-5-1710 \\
22-5-1710\end{array}$ & $\begin{array}{l}\text { Gabriel } \\
\text { Dalmau / } \\
\text { Fr. Tomás } \\
\text { Llanés }\end{array}$ & $\begin{array}{c}\text { Fr. Pere M. Sama- } \\
\text { sada/ Fr. Pere M. } \\
\text { Monjo }\end{array}$ & $\begin{array}{c}\text { Juan } \\
\text { Camps, } \\
\text { Can. / Josep } \\
\text { Pujol, D.T. } \\
\text { benef. // An- } \\
\text { toni Palla- } \\
\text { res, U.I.D. } \\
\text { / Francisco } \\
\text { Font, estu- } \\
\text { diante }\end{array}$ & $\begin{array}{c}\text { Cl. de la } \\
\text { Ciudad } \\
\text { de Ma- } \\
\text { llorca }\end{array}$ \\
\hline
\end{tabular}




\begin{tabular}{|c|c|c|c|c|c|c|}
\hline NOMBRE & GRADO & FECHA & $\begin{array}{l}\text { RECTOR / } \\
\text { PADRINO }\end{array}$ & $\begin{array}{l}\text { EXAMINA- } \\
\text { DORES }\end{array}$ & TESTIGOS & $\begin{array}{l}\text { PROCE- } \\
\text { DENCIA }\end{array}$ \\
\hline $\begin{array}{c}\text { Josep } \\
\text { Vilanova }\end{array}$ & $\begin{array}{l}\text { L. T. } \\
\\
\text { D. T. } \\
\text { Nem. } \\
\text { Disc. }\end{array}$ & $\begin{array}{l}20-6-1710 \\
20-6-1710\end{array}$ & $\begin{array}{l}\text { Gabriel } \\
\text { Dalmau / } \\
\text { Fr. Tomás } \\
\text { Llanés }\end{array}$ & $\begin{array}{l}\text { Fr. Pere M. Sama- } \\
\text { sada / Fr. Ramon } \\
\text { Bages }\end{array}$ & $\begin{array}{c}\text { Antonio de } \\
\text { Bordons i } \\
\text { Tomassa } \\
\text { / Ramón } \\
\text { Torrent, } \\
\text { estudiantes } \\
\text { // Antonio } \\
\text { Font, es- } \\
\text { tudiante / } \\
\text { Celedonio } \\
\text { Trepasso, } \\
\text { zapatero. }\end{array}$ & $\begin{array}{l}\text { Acóllito } \\
\text { de Banat, } \\
\text { Urgell }\end{array}$ \\
\hline $\begin{array}{l}\text { Esteban } \\
\text { Silvestre }\end{array}$ & $\begin{array}{l}\text { L. T. } \\
\\
\text { D. T. } \\
\text { Nem. } \\
\text { Disc. }\end{array}$ & $\begin{array}{l}18-8-1710 \\
19-8-1710\end{array}$ & $\begin{array}{c}\text { Gabriel } \\
\text { Dalmau / } \\
\text { Fr. Pere M. } \\
\text { Monjo }\end{array}$ & $\begin{array}{l}\text { Fr. Pere M. Sama- } \\
\text { sada / Fr. Ramon } \\
\text { Bages }\end{array}$ & $\begin{array}{c}\text { Bartolomé } \\
\text { Prades / An- } \\
\text { drés Prades, } \\
\text { hermanos, } \\
\text { studs. del } \\
\text { Valle de } \\
\text { Arán, Urgell } \\
\text { // Josep } \\
\text { Folch D. } \\
\text { T. / Tomás } \\
\text { Villaró, D. } \\
\text { T. Solsona }\end{array}$ & O.P. \\
\hline $\begin{array}{c}\text { Josep } \\
\text { Indilla }\end{array}$ & $\begin{array}{l}\text { L. C. } \\
\\
\text { D. C. } \\
\text { Nem. } \\
\text { Disc. }\end{array}$ & $19-8-1710$ & $\begin{array}{c}\text { Gabriel } \\
\text { Dalmau } \\
\text { / Antoni } \\
\text { Pallarés, } \\
\text { U.I.D. }\end{array}$ & $\begin{array}{c}\text { Josep Folch / } \\
\text { Tomás Villaro, } \\
\text { Doctores }\end{array}$ & $\begin{array}{c}\text { Bartolomé } \\
\text { Prades / An- } \\
\text { drés Prades, } \\
\text { hermanos, } \\
\text { studs. del } \\
\text { Valle de } \\
\text { Arán, Urgell } \\
\text { // Josep } \\
\text { Grau / An- } \\
\text { tonio Llull, } \\
\text { estudiantes }\end{array}$ & $\begin{array}{l}\text { Pbro. de } \\
\text { Cervera }\end{array}$ \\
\hline $\begin{array}{l}\text { Magí } \\
\text { Bagués }\end{array}$ & $\begin{array}{l}\text { L. T. } \\
\\
\text { D. T. } \\
\text { Nem. } \\
\text { Disc. }\end{array}$ & $\begin{array}{l}22-10-1710 \\
23-10-1710\end{array}$ & $\begin{array}{c}\text { Gabriel } \\
\text { Dalmau/ } \\
\text { Fr. Ramon } \\
\text { Bages }\end{array}$ & $\begin{array}{l}\text { Fr. Tomàs Llanés/ } \\
\text { Fr. Esteban Sil- } \\
\text { vestre }\end{array}$ & $\begin{array}{c}\text { Francisco } \\
\text { Carulla, Vi- } \\
\text { cario de St. } \\
\text { Miguel de } \\
\text { Castelluell } \\
\text { y doctor/ } \\
\text { Joan Desfil, } \\
\text { negociante } \\
\text { de Tarrago- } \\
\text { na. Francis- } \\
\text { co Carulla } \\
\text { / Pere Joan } \\
\text { Cardona, } \\
\text { benef. de } \\
\text { Solsona. }\end{array}$ & $\begin{array}{c}\text { Pbro. de } \\
\text { la villa } \\
\text { de Pons, } \\
\text { Rector de } \\
\text { Iglesia de } \\
\text { la Torra, } \\
\text { Urgell }\end{array}$ \\
\hline
\end{tabular}




\begin{tabular}{|c|c|c|c|c|c|c|}
\hline NOMBRE & GRADO & FECHA & $\begin{array}{l}\text { RECTOR / } \\
\text { PADRINO }\end{array}$ & $\begin{array}{l}\text { EXAMINA- } \\
\text { DORES }\end{array}$ & TESTIGOS & $\begin{array}{l}\text { PROCE- } \\
\text { DENCIA }\end{array}$ \\
\hline $\begin{array}{l}\text { Josep } \\
\text { Grau }\end{array}$ & $\begin{array}{l}\text { L. T. } \\
\text { D. T. } \\
\text { Nem. } \\
\text { Disc. }\end{array}$ & $\begin{array}{l}24-10-1710 \\
25-10-1710\end{array}$ & $\begin{array}{l}\text { Fr. Ramon } \\
\text { Bages, } \\
\text { Vice-rector } \\
\text { / Fr. Pere } \\
\text { Monjo }\end{array}$ & $\begin{array}{l}\text { Fr. Esteban Silves- } \\
\text { tre / Josep Pujol, } \\
\text { Benef. de Solsona }\end{array}$ & $\begin{array}{c}\text { Antonio } \\
\text { del Gra- } \\
\text { ner, Pbro./ } \\
\text { Jaime Pla, } \\
\text { subDiác. de } \\
\text { Solsona }\end{array}$ & $\begin{array}{l}\text { Pbro. de } \\
\text { Solsona }\end{array}$ \\
\hline $\begin{array}{l}\text { Josep } \\
\text { Ruet }\end{array}$ & $\begin{array}{l}\text { D. T. } \\
\text { Nem. } \\
\text { Disc. }\end{array}$ & $\begin{array}{l}15-1-1711 \\
16-1-1711\end{array}$ & $\begin{array}{l}\text { Gabriel } \\
\text { Dalmau, } \\
\text { Rector/ Fr. } \\
\text { Pere M. } \\
\text { Monjo }\end{array}$ & $\begin{array}{c}\text { Fr. Ramon Bages } \\
\text { / Fr. Esteban Sil- } \\
\text { vestre }\end{array}$ & $\begin{array}{c}\text { Dr. Josep } \\
\text { Grau/ An- } \\
\text { tonio del } \\
\text { Graner, } \\
\text { Pbro. de } \\
\text { Solsona // } \\
\text { Francisco } \\
\text { Llanes / } \\
\text { Antonio } \\
\text { Bordons, } \\
\text { profs. Teo- } \\
\text { logia. }\end{array}$ & \\
\hline $\begin{array}{c}\text { Josep } \\
\text { Abadal }\end{array}$ & $\begin{array}{l}\text { L. Ph. } \\
\text { D. Ph. } \\
\text { Nem. } \\
\text { Disc. }\end{array}$ & $\begin{array}{l}22-5-1711 \\
23-5-1711\end{array}$ & $\begin{array}{l}\text { Gabriel } \\
\text { Dalmau, } \\
\text { Rector/ } \\
\text { Fr. Ramon } \\
\text { Bages }\end{array}$ & $\begin{array}{l}\text { Fr. Pere M. Monjo/ } \\
\text { Esteban Silvestre }\end{array}$ & $\begin{array}{c}\text { Carlos } \\
\text { Cortés, } \\
\text { cerero/ Es- } \\
\text { teban Pensí, } \\
\text { mulero de } \\
\text { Solsona // } \\
\text { Fr. Josep } \\
\text { Vila/ Fr. } \\
\text { Ramón } \\
\text { Llorens }\end{array}$ & $\begin{array}{l}\text { Pbro. de } \\
\text { Calaf }\end{array}$ \\
\hline $\begin{array}{l}\text { Josep Joan } \\
\text { Riquer }\end{array}$ & $\begin{array}{l}\text { L. M. } \\
\text { D. M. } \\
\text { Nem. } \\
\text { Disc. }\end{array}$ & $\begin{array}{l}11-9-1711 \\
11-9-1711\end{array}$ & $\begin{array}{c}\text { Gabriel } \\
\text { Dalmau / }\end{array}$ & $\begin{array}{c}\text { Bernardino Parent, } \\
\text { D. M. / Pedro } \\
\text { Pujol, D. M. }\end{array}$ & $\begin{array}{l}\text { Carlos Cor- } \\
\text { tés, cerero/ } \\
\text { Jerónimo } \\
\text { Fita, de } \\
\text { Solsona // } \\
\text { Isidro Font, } \\
\text { D. T, de la } \\
\text { Llena / Jo- } \\
\text { sep Vilar, de } \\
\text { Cambrils. }\end{array}$ & $\begin{array}{c}\text { De Ibiza, } \\
\text { Diócesis } \\
\text { de Tarra- } \\
\text { gona }\end{array}$ \\
\hline $\begin{array}{l}\text { Miguel } \\
\text { Barceló }\end{array}$ & $\begin{array}{l}\text { L. T. } \\
\text { D. T. } \\
\text { Nem. } \\
\text { Disc. }\end{array}$ & $\begin{array}{l}18-9-1711 \\
18-9-1711\end{array}$ & $\begin{array}{c}\text { Gabriel } \\
\text { Dalmau, } \\
\text { / Fr. Pere } \\
\text { Mtr. Monjo }\end{array}$ & $\begin{array}{c}\text { Fr. Ramon Bages } \\
\text { / Fr. Esteban Sil- } \\
\text { vestre }\end{array}$ & $\begin{array}{c}\text { Josep Bo- } \\
\text { tines D.T. } \\
\text { / Cosme } \\
\text { Guiot, } \\
\text { Pbros. de } \\
\text { Solsona // } \\
\text { Francisco } \\
\text { Font/ An- } \\
\text { tonio Bor- } \\
\text { dons, profs. } \\
\text { de Theol. }\end{array}$ & $\begin{array}{l}\text { Pbro. } \\
\text { Benef. } \\
\text { de Ciu- } \\
\text { tadella, } \\
\text { Menorca }\end{array}$ \\
\hline
\end{tabular}




\begin{tabular}{|c|c|c|c|c|c|c|}
\hline NOMBRE & GRADO & FECHA & $\begin{array}{l}\text { RECTOR / } \\
\text { PADRINO }\end{array}$ & $\begin{array}{l}\text { EXAMINA- } \\
\text { DORES }\end{array}$ & TESTIGOS & $\begin{array}{l}\text { PROCE- } \\
\text { DENCIA }\end{array}$ \\
\hline $\begin{array}{c}\text { Salvador } \\
\text { Francisco } \\
\text { Serra }\end{array}$ & $\begin{array}{l}\text { L. T. } \\
\text { D. T. } \\
\text { Nem. } \\
\text { Disc. }\end{array}$ & $\begin{array}{l}17-7-1712 \\
18-7-1712\end{array}$ & $\begin{array}{c}\text { Fr. Pere M. } \\
\text { Samasada/ } \\
\text { Fr. Pere M. } \\
\text { Monjo }\end{array}$ & $\begin{array}{l}\text { Fr. Ramon Bages, } \\
\text { D. T. / Fr. Esteban } \\
\text { Silvestre, D. T. }\end{array}$ & $\begin{array}{c}\text { Tomás } \\
\text { Pegullá, } \\
\text { zapatero / } \\
\text { Antonio } \\
\text { Vallonga, } \\
\text { agricultor / } \\
\text { Antoni Pal- } \\
\text { larés, U.I.D. } \\
\text { / Antonio } \\
\text { Cases, stud. }\end{array}$ & $\begin{array}{l}\text { Diác. de } \\
\text { Sa Pobla, } \\
\text { Mallorca }\end{array}$ \\
\hline $\begin{array}{l}\text { Jerónimo } \\
\text { Ardén }\end{array}$ & $\begin{array}{l}\text { L. T. } \\
\text { D. T. } \\
\text { Nem. } \\
\text { Disc. }\end{array}$ & $\begin{array}{l}1-9-1712 \\
1-9-1712\end{array}$ & $\begin{array}{c}\text { Fr. Pere M. } \\
\text { Samasada/ } \\
\text { Fr. Pere } \\
\text { Mtr. Monjo }\end{array}$ & $\begin{array}{l}\text { Fr. Ramon Bages } \\
\text { / Fr. Esteban Sil- } \\
\text { vestre }\end{array}$ & $\begin{array}{c}\text { Bernardo } \\
\text { Tapia, } \\
\text { zapatero / } \\
\text { Salvador } \\
\text { Canal, stud. } \\
\text { en Solsona } \\
\text { // Domingo } \\
\text { Cerch, Diác. } \\
\text { / Jaume Pa- } \\
\text { rent, D. T., } \\
\text { profesor. }\end{array}$ & $\begin{array}{l}\text { Cl. de } \\
\text { Solsona }\end{array}$ \\
\hline $\begin{array}{l}\text { Juan } \\
\text { Bautista } \\
\text { Forner }\end{array}$ & $\begin{array}{l}\text { D. T. } \\
\text { Nem. } \\
\text { Disc. }\end{array}$ & 23-11-1712 & $\begin{array}{c}\text { Fr. Pere M. } \\
\text { Samasada/ } \\
\text { Fr. Ramon } \\
\text { Bages }\end{array}$ & $\begin{array}{l}\text { Fr. Pere M. Monjo } \\
\text { / Fr. Esteban Sil- } \\
\text { vestre }\end{array}$ & $\begin{array}{c}\text { Melchor } \\
\text { Tella, Prior } \\
\text { de St. Juan } \\
\text { de Frontan- } \\
\text { ya / Gaspar } \\
\text { Costa, } \\
\text { agricultor } \\
\text { de Solsona } \\
\text { / Pere M. } \\
\text { Coma, } \\
\text { sustituto. // } \\
\text { Pere Joan } \\
\text { Cardona, } \\
\text { Pbro. D. T. } \\
\text { / Francisco } \\
\text { Font, Sub- } \\
\text { Diác. de } \\
\text { Solsona } \\
\text { y prof. de } \\
\text { Theol. }\end{array}$ & $\begin{array}{c}\text { Pbro. } \\
\text { Benef. } \\
\text { de Seo } \\
\text { de Ibiza, } \\
\text { Diócesis } \\
\text { de Tarra- } \\
\text { gona }\end{array}$ \\
\hline
\end{tabular}




\begin{tabular}{|c|c|c|c|c|c|c|}
\hline NOMBRE & GRADO & FECHA & $\begin{array}{l}\text { RECTOR / } \\
\text { PADRINO }\end{array}$ & $\begin{array}{l}\text { EXAMINA- } \\
\text { DORES }\end{array}$ & TESTIGOS & $\begin{array}{l}\text { PROCE- } \\
\text { DENCIA }\end{array}$ \\
\hline $\begin{array}{l}\text { Ramón } \\
\text { Castelló }\end{array}$ & $\begin{array}{l}\text { L. T. } \\
\text { D. T. } \\
\text { Nem. } \\
\text { Disc. }\end{array}$ & $\begin{array}{l}27-3-1713 \\
28-3-1713\end{array}$ & $\begin{array}{l}\text { Fr. Pere M. } \\
\text { Samasada/ } \\
\text { Fr. Ramon } \\
\text { Bages }\end{array}$ & $\begin{array}{c}\text { Fra. Pere M. } \\
\text { Monjo, D. T. / Fr. } \\
\text { Esteban Silvestre, } \\
\text { D. T. }\end{array}$ & $\begin{array}{c}\text { Pere M. } \\
\text { Coma, } \\
\text { sustituto de } \\
\text { Bernardo } \\
\text { Coma / } \\
\text { Pedro Rovi- } \\
\text { ra, cirujano } \\
\text { / Pedro Far, } \\
\text { stud. de } \\
\text { Biosca // } \\
\text { Pedro Rovi- } \\
\text { ra, cirujano } \\
\text { / Josep } \\
\text { Sebrià, } \\
\text { estudiante }\end{array}$ & $\begin{array}{l}\text { Pbro. de } \\
\text { Cervera }\end{array}$ \\
\hline $\begin{array}{c}\text { Francisco } \\
\text { Font }\end{array}$ & $\begin{array}{l}\text { L. T. } \\
\text { D. T. } \\
\text { Nem. } \\
\text { Disc. }\end{array}$ & $\begin{array}{l}30-10-1713 \\
30-10-1713\end{array}$ & $\begin{array}{l}\text { Fr. Pere M. } \\
\text { Samasada / } \\
\text { Fr. Pere M. } \\
\text { Monjo }\end{array}$ & $\begin{array}{l}\text { Fr. Ramon Bages, } \\
\text { D. T. / Fr. Esteban } \\
\text { Silvestre, D. T. }\end{array}$ & $\begin{array}{l}\text { Pere Mártir } \\
\text { Coma, } \\
\text { sustituto, } \\
\text { Josep Cases } \\
\text { y Antonio } \\
\text { Salvador, } \\
\text { profs. de } \\
\text { Phil.. // } \\
\text { Josep Va- } \\
\text { llonga, Luis } \\
\text { Pallares, } \\
\text { Pbros. y } \\
\text { D. T. }\end{array}$ & $\begin{array}{l}\text { Diác. de } \\
\text { Solsona }\end{array}$ \\
\hline $\begin{array}{l}\text { Josep } \\
\text { Janer }\end{array}$ & $\begin{array}{l}\text { L. T. } \\
\text { D. T. } \\
\text { Nem. } \\
\text { Disc. }\end{array}$ & $\begin{array}{l}11-11-1713 \\
\text { Hora tertia }\end{array}$ & $\begin{array}{l}\text { Fr. Pere M. } \\
\text { Samasa- } \\
\text { daRector / } \\
\text { Fr. Ramon } \\
\text { Bages }\end{array}$ & $\begin{array}{c}\text { Fr. Pere M. Monjo, } \\
\text { D. T. / Fr. Esteban } \\
\text { Silvestre, D. T. }\end{array}$ & $\begin{array}{l}\text { Josep Va- } \\
\text { llonga, D. T. } \\
\text { / Francisco } \\
\text { Pujor, prof. } \\
\text { de Gram., } \\
\text { Pedro M. } \\
\text { Coma, } \\
\text { sustituto de } \\
\text { Bernardo } \\
\text { Coma. }\end{array}$ & $\begin{array}{l}\text { Pbro. de } \\
\text { Cervera }\end{array}$ \\
\hline
\end{tabular}




\begin{tabular}{|c|c|c|c|c|c|c|}
\hline NOMBRE & GRADO & FECHA & $\begin{array}{l}\text { RECTOR / } \\
\text { PADRINO }\end{array}$ & $\begin{array}{l}\text { EXAMINA- } \\
\text { DORES }\end{array}$ & TESTIGOS & $\begin{array}{l}\text { PROCE- } \\
\text { DENCIA }\end{array}$ \\
\hline $\begin{array}{l}\text { Domingo } \\
\text { de Aus- } \\
\text { mendi }\end{array}$ & L. T. & $\begin{array}{l}2-8-1714 \\
3-8-1714\end{array}$ & $\begin{array}{c}\text { Fr. Pere M. } \\
\text { Samasada/ } \\
\text { Pere Joan } \\
\text { Cardona, } \\
\text { Vicario } \\
\text { prepetuo }\end{array}$ & $\begin{array}{l}\text { Fr. Pere M. Monjo, } \\
\text { D. T. / Fr. Esteban } \\
\text { Silvestre, D. T. }\end{array}$ & $\begin{array}{c}\text { Antonio } \\
\text { Coma, } \\
\text { sustituto de } \\
\text { Bernardo } \\
\text { Coma / } \\
\text { Pablo Alin- } \\
\text { ya, D.T. } \\
\text { / Andrés } \\
\text { Badich, sas- } \\
\text { tre // Antoni } \\
\text { Pallarés, } \\
\text { U.I.D., D.T. } \\
\text { / Pedro } \\
\text { Rovira, } \\
\text { cirujano. }\end{array}$ & $\begin{array}{c}\text { Pbro. } \\
\text { de Vi- } \\
\text { llarreal, } \\
\text { Diócesis } \\
\text { Pamplo- } \\
\text { na }\end{array}$ \\
\hline $\begin{array}{l}\text { * Anto- } \\
\text { nino } \\
\text { Genée }\end{array}$ & $\begin{array}{l}\text { L. T. } \\
\\
\text { D. T. } \\
\text { Nem. } \\
\text { Disc. }\end{array}$ & $31-12-1715$ & $\begin{array}{c}\text { Fr. Pere M. } \\
\text { Samasada/ } \\
\text { Fr. Esteban } \\
\text { Silvestre }\end{array}$ & $\begin{array}{l}\text { Fr. Ramon Bages / } \\
\text { Fr. Pere M. Monjo }\end{array}$ & $\begin{array}{c}\text { Jeroni Riu, } \\
\text { pelaire / } \\
\text { Francisco } \\
\text { Vila, satre } \\
\text { de Solsona } \\
\text { // Bernar- } \\
\text { do Tapia, } \\
\text { cordelero } \\
\text { / Gaspar } \\
\text { Busquets / } \\
\text { tejedor de } \\
\text { paños, de } \\
\text { Solsona }\end{array}$ & $\begin{array}{c}\text { O. P. } \\
\text { De la } \\
\text { Provincia } \\
\text { de la } \\
\text { Germania } \\
\text { Inferior }\end{array}$ \\
\hline
\end{tabular}

\section{BibliOgRAFÍA CITADA}

AAVV (1927), Enciclopedia universal ilustrada europeo-americana, vol. 57, Madrid, Hijos de J. Espasa.

Ajo, Cándido M. (1959), Historia de las universidades hispánicas: orígenes y desarrollo desde su aparición hasta nuestros días, III, Ávila, CSIC.

Ajo, Cándido M. (1963), Historia de las universidades hispánicas: orígenes y desarrollo desde su aparición hasta nuestros días, IV, Ávila, CSIC.

Ajo, Cándido M. (1966), Historia de las universidades hispánicas: orígenes y desarrollo desde su aparición hasta nuestros días, V, Ávila, CSIC.

Albareda Salvadó, Joaquim (2005), "Els exiliats catalans de finals del segle XVII i principis del XVIII en els Comtats: Barretines, Botiflers, Carrasclets" en A. Charlon y P. Piginet (eds.), Les exils catalans en France, Paris, Presses Sorbonne, pp. 51-64.

Alcoberro, Agustí (2002), L'exili austracista (1713-1747), Barcelona, Fundació Noguera, Vol. 1.

Anónimo (1904), La Diócesis de Solsona, 1904, Barcelona, Tobella \& Costa. 
Beltrán de Heredia, Vicente (1955), "Reseña de J. Serra Vilaró, Universidad Literaria de Solsona", La Ciencia Tomista, 82, p. 499.

Beltrán de Heredia, Vicente (1958), “Catálogo de los colegiales, lectores y rectores del Colegio de San Miguel de Solsona (1615-1835)", Analecta Sacra Tarraconensia, 31, pp. 125-137.

Bover, Joaquín M. (1868), Biblioteca de autores baleares, Palma, Impr. De Gelabert, II.

Cassanyes Roig, Albert y Ramis Barceló, Rafael (2014), “Los graduados en Artes y Filosofía en la Universidad Luliana y Literaria de Mallorca I: (1692-1750)", Tiempos modernos, 28, pp. 1-46.

Collell, Alberto (1960), “Fundación del colegio de San Vicente y San Raimundo, de Barcelona", Analecta Sacra Tarraconensia, XXXII, pp. 309-331.

De la Fuente, Vicente (1970), Historia de las universidades, colegios y demás establecimientos de enseñanza en España, II, [Madrid, 1885], Frankfurt am Main, Verlag Sauer \& Auvermann.

Dietari de la Generalitat de Catalunya (1994), J. M. Sans Travé (ed.), vol. 10, Barcelona, Departament de Presidència.

Escartín Sánchez, Eduardo, "Universidades mayores y menores. Una polémica en la Cataluña del siglo XVII", Pedralbes, 23 (2003), pp. 187-202.

Esteve Perendreu, Francesc (2007), Mestrescoles i rectors de l'Estudi General de Lleida (1597-1717), Lleida, Edicions de la Universitat de Lleida.

Fernández de las Cuevas, Ruperto (1852), La voz del siglo, Madrid, Imprenta de Manuel Minuesa.

Florensa i Parés, Joan (2010), El Projecte educatiu de l'Escola Pia de Catalunya (1683-2003): una escola popular, Barcelona, IEC.

Folch, Artemi (1972), Les universitats de Catalunya al tombant del segle XVII, Barcelona, Dalmau.

García Cárcel, Ricardo (1985), Historia de Cataluña. Siglos XVI y XVII. Los caracteres originales de la historia de Cataluña, vol. 1, Barcelona, Ariel.

Guerra, Juan Carlos de (1928), Ensayo de un padrón histórico Guipúzcoa, según el orden de sus famllias pobladoras, San Sebastián, Ed. J. Muñoz-Baroja.

Hernández Morejón, Antonio (1842), Historia bibliográfica de la medicina española, II, Madrid, Vda. de Jordán e hijos.

Lahoz Finestres, José M. (1997), “Graduados catalanes en las facultades de Leyes y Cánones de la Universidad de Huesca”, Estudis històrics $i$ documents dels arxius de protocols, 15, pp. 167-220.

Lahoz Finestres, José M. y Gort Riera, Roser (2002), “Orientación bibliográfica sobre las Universidades de la Corona de Aragón” en J. J. Busqueta y J. Pemán (coord.), Les universitats de la Corona d'Aragó, ahir i avui, Lleida, Pòrtic, pp. 603-665.

Llorens i Solé, Antoni (1978), "La Universidad literaria de Solsona: 1620-1717”, en AAVV, Primer Simposium Nacional sobrelos antiguos centros docentes españoles, Lleida, Imprenta Provincial, pp. 95-101. 
Madoz, Pascual (1847), Diccionario geográfico-estadístico-histórico de España y sus posesiones de ultramar, tomo VI, Madrid, Est. lit.-tip. de P. Madoz y L. Sagasti.

Molas Ribalta, Pere (2008), "Família, amics i canvis en la Guerra de Successió", Pedralbes, 28, Actes del VI Congrés d'Història Moderna de Catalunya: "La Catalunya diversa" (15-19 de desembre de 2008), pp. 263-280.

Montañà i Buchaca, Daniel (1988), "Els estudis de medicina a la Universitat Literària de Solsona", Gimbernat: revista catalana d'història de la medicina i de la ciència, 8, pp. 247-256.

Ochoa Brun, Miguel Ángel (2002), Embajadas rivales. La presencia diplomática de España en Italia durante la Guerra de Sucesión, Madrid, Real Academia de la Historia.

Parramon Doll, Antonio (1975), "Noticias universitarias menos conocidas de las ciudades ilerdenses. Lérida, Cervera, Seo de Urgel, Solsona y Tremp", Los antiguos centros docentes españoles: comunicaciones presentadas en el Pleno de la Asamblea celebrado en San Sebastian, los dias 9 al 11 de diciembre de 1971, pp. 201-212.

Planells i Ripoll, Joan (1995), “L'ensenyament a Eivissa fins a 1864”, Eivissa, 26, pp. 59-63.

Planells i Ripoll, Joan (1996), “Metges de les Pitiüses”, Eivissa, 28 pp. 160-165.

Planes i Albets, Ramon (1984), “Aportació a l'estudi de la Universitat de Solsona (1620-1717) i notes sobre les seves fonts documentals: els estatuts de 1661" en AAVV, Terres de Lleida al segle XVII: miscel-lània Lleida: Institut d'Estudis Ilerdencs, Diputació Provincial, pp. 369-374.

Planes i Albets, Ramon (2016), L'Hospital d'en Llobera. Lectures d'història de Solsona, Solsona, Forum d'Aprofundiment democràtic, 2 vols.

Ponz, Antonio (1788), Viage de España, en que se da noticia de las cosas mas apreciables, y dignas de saberse, que hay en ella, tomo XIV, Madrid, Por la Viudad de Ibarra, Hijos y Compañía.

Querol Coll, Enric (2013), L'Antiga Universitat a Tortosa (1529-1824), Tortosa, Antena Cultural Tortosa-Universitat Rovira i Virgili.

Ramis Barceló, Rafael (2013), "Las cátedras tomistas de la Universidad Luliana y Literaria de Mallorca (1692-1824)", Archivum Fratrum Praedicatorum, 83, 345-368.

Ramis Barceló, Rafael (2014a), "Las cátedras lulianas de la Universidad de Mallorca (1692-1824)", Bolletí de la Societat Arqueològica Lul-liana, 70, 185-205.

Ramis Barceló, Rafael (2014b), "Las cátedras suaristas de la Universidad Luliana y Literaria de Mallorca (1692-1767)", Archivum Historicum Societatis Iesu, 164/2, pp. 399-426.

Ramis Barceló, Rafael (2015a), "Sobre los privilegios de la Universidad de Solsona y los grados en leyes, cánones y medicina durante el siglo XVII", Glossae. European Journal of Legal History 12, pp. 661-678. 
Ramis Barceló, Rafael (2015b), "Las cátedras escotistas de la Universidad Luliana y Literaria de Mallorca (1692-1824)", Archivum Franciscanum Historicum, 108/1-2, pp. 301-317.

Ramis Barceló, Rafael (2016) “La Facultad de Leyes y Cánones de la Universidad de Barcelona a comienzos del siglo XVIII", Anuario de Historia del Derecho Español, 86, pp. 305-408.

Ramis Barceló, Rafael (2017), Doctores hispanos en Leyes y Cánones por la Universidad de la Sapienza de Roma (1549-1774), Madrid, Dykinson.

Ramis y Ramis, Juan (1817), Varones ilustres de Menorca y noticia de los apellidos que mas se han distinguido en ella, Mahón, Imprenta Serra.

Sanahuja, Pedro (1944), Historia de la beneficencia en Lérida, Vol. I, Lérida, Instituto de Estudios Ilerdenses.

Serra Vilaró, Juan (1953), Universidad Literaria de Solsona, Tarragona, Hermanos Sugrañes.

Torres Amat, Félix (1836), Memorias para ayudar a formar un diccionario crítico de escritores catalanes, Barcelona, Imprenta Verdaguer.

Vicens Vives, Jaime (1961), Historia del España y América, vol. 3, Barcelona, Vicens Vives.

Villanueva, Jaime (1821), Viage literario a las iglesias de España: Viage a Solsona, Ager y Urgel: 1806 y 1807, vol. 9, Madrid, Imprenta Real.

Fecha de recepción del artículo: 21 de septiembre de 2016

Fecha de aceptación y versión final: 26 de enero de 2017 
